
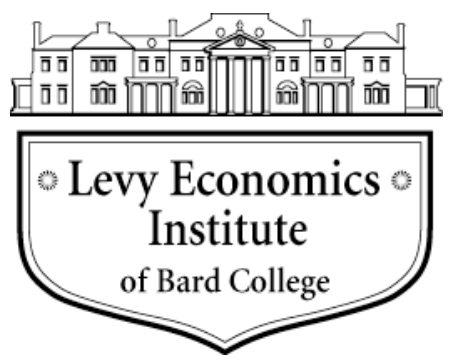

Working Paper No. 692

\title{
Quality of Match for Statistical Matches Used in the Development of the Levy Institute Measure of Time and Income Poverty (LIMTIP) for Argentina, Chile, and Mexico
}

by

Thomas Masterson

Levy Economics Institute of Bard College

October 2011

The Levy Economics Institute Working Paper Collection presents research in progress by Levy Institute scholars and conference participants. The purpose of the series is to disseminate ideas to and elicit comments from academics and professionals.

Levy Economics Institute of Bard College, founded in 1986, is a nonprofit, nonpartisan, independently funded research organization devoted to public service. Through scholarship and economic research it generates viable, effective public policy responses to important economic problems that profoundly affect the quality of life in the United States and abroad.

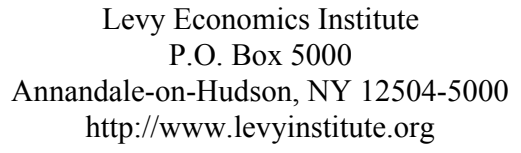




\begin{abstract}
The quality of match of three statistical matches used in the LIMTIP estimates for Argentina, Chile, and Mexico is described. The first match combines the 2005 Uso del Tiempo (UT 2005) with the 2006 Encuesto Annual de Hogares (EAH) for Argentina. The second match combines the 2007 Encuesta Experimental sobre Uso del Tiempo en el Gran Santiago (EUT 2007) with the 2006 Encuesta Caracteristización Socioeconómica Nacional (CASEN 2006) for Chile. The third match combines the 2008 Encuesta Nacional de Ingresos y Gastos de los Hogares (ENIGH 2008) with the 2009 Encuesta Nacional sobre Uso del Tiempo (ENUT 2009) for Mexico. In each case, the alignment of the two datasets is examined, after which various aspects of the match quality are described. In each case, the matches are of high quality, given the nature of the source datasets.
\end{abstract}

Keywords: Statistical Matching; Time Use; Household Production; Poverty; LIMTIP; Argentina; Chile; Mexico

JEL Classifications: C14, C40, D31, J22 


\section{INTRODUCTION}

This paper describes the construction of synthetic datasets created for use in estimation of the Levy Institute Measure of Time and Income Poverty (LIMTIP) for Argentina, Chile, and Mexico. This work was carried out for a project supported by the United Nations Development Programme and the International Labor Organization to develop alternatives to conventional income poverty thresholds. ${ }^{1}$ Construction of LIMTIP estimates requires a variety of information for households. In addition to basic demographics, the estimation process requires information about income and time use. No single dataset has all the required data for any of the three countries. Thus, in order to produce LIMTIP estimates, a synthetic data file is created for each country by combining two source datasets with statistical matching. ${ }^{2}$ For Argentina, we use the Dirección General de Estadística y Censos’ Encuesto Annual de Hogares (EAH) as the base dataset, since it contains good information on demographics, income, transfers and taxes for a representative sample of households in Buenos Aires. Time use data comes from the DGEC's time use module of the same survey (UT). For Chile, we use the Encuesta de Caracterización Socioeconómica Nacional (CASEN) as the base dataset since it contains good information on demographics, income, transfers, and taxes for a representative sample of households in Chile. For the time use data, we use the Encuesta Experimental sobre Uso del Tiempo en el Gran Santiago (EUT), which covers only Greater Santiago de Chile. For Mexico, we use the Encuesta Nacional de Ingresos y Gastos de los Hogares (ENIGH) as the base dataset, matching it with the Encuesta Nacional sobre Uso del Tiempo (ENUT), which includes rich time use data. Both of the Mexican datasets cover the entire country.

This paper is organized as follows. Each section of the paper details the statistical match for each country in turn. The source datasets are described and their demographic characteristics are compared. Then the quality of the match is reviewed for each.

\footnotetext{
${ }^{1}$ The project, titled "Why Time Deficits Matters: Implications for Poverty Measurement and Poverty Reduction Strategies,” is directed by Ajit Zacharias and Rania Antonopoulos.

${ }^{2}$ See Kum and Masterson (2010) for details of the statistical matching procedure that we use.
} 


\section{ARGENTINA}

\section{Data and Alignment}

The source datasets for the time use match for the LIMTIP estimates for Argentina are the 2005 EAH and the 2005 UT. Note that our study is confined to the city of Buenos Aires, since that is the coverage of the EAH and UT. We use individual records from the 2005 EAH file, excluding those living in group quarters or in the Armed Forces. The EAH has a number of missing values, which we replaced by the method of multiple imputation with hot-decking. ${ }^{3}$ This results in five replicates for each original record, for a total of 76,260, representing 2,696,930 individuals in Buenos Aires. Since the UT covers individuals aged 15 to 74 years old, we discard younger and older individuals from the EAH file. An additional detail concerns the sampling done on the UT: only one individual in each household is surveyed. Therefore, we will have no good way to compare household totals of household production, other than at the aggregate level. This leaves 57,335 records, which represents 2,044,405 individuals when weighted.

In order to create the estimates of the time-income poverty measure, we had to construct thresholds for the time spent on household production. The thresholds are defined for the household. The reference group in constructing the thresholds consists of households with at least one nonemployed adult and income around the official income-poverty line. We divided the reference group into 12 subgroups based on the number of children $(0,1,2$, and 3 or more) and number of adults (1, 2, and 3 or more) for calculating the thresholds. The thresholds are simply the average values of the time spent on household production by households, differentiated by the number of adults and children. In principle, they represent the average amount of household production that is required to subsist at the poverty-level of income.

For practical purposes, we defined the reference group as households with household incomes between $75 \%$ and $150 \%$ of the poverty line (this range is referred to as the poverty band hereafter), and with at least one nonemployed adult. In order to transfer the hours spent by individuals on household production in the reference group as closely as possible, we used the following strata variables in the match: indicators for being within the poverty band, for having one or more nonemployed adults in the household, the number of children, the number of adults,

\footnotetext{
${ }^{3}$ The variables with missing values were industry, occupation, educational attainment, as well as all of the income variables. 3,888 of 15,252 records had missing values for one or more of these variables.
} 
sex, employment status, and household income category. Table 1 compares the distribution of individuals by these variables in the two datasets. Since one survey (time use) was carried out as a subset of the other (income and demographic), we can expect them to be well-aligned. We see that there are 3\% fewer individuals in households without children in the time use sample than in the overall survey. Individuals in three-adult households make up a greater share of those in the time use survey, while those in one-adult and five-or-more adult households are more common in the EAH. About 3\% fewer individuals are in households with at least one nonemployed adult in the time use survey, compared to the overall survey, though the difference in the number of individuals in households within the poverty band in the two surveys is less than $1 \%$. The distribution by household income is very close between the two surveys, with all categories differing by $1.7 \%$ or less. The nonemployed are underrepresented in the UT relative to the EAH (3\%). The distribution of individuals by sex is close in the two surveys, with females slightly less common (1.4\%) in the EAH than in the UT. So, as expected, we have a very close alignment between the two surveys along all seven strata variables.

\section{Match QC}

Turning to the results of the match, we first look to the distribution of matched records by matching round in Table 2. The bulk of the matches, 68.9\%, occur in the first round. This is lower than in other time use matches (see, for example, Masterson 2010), due to the higher than usual number of strata variables used in this match. ${ }^{4}$ The rest of the records are matched over an additional fourteen rounds, with $5.8 \%$ receiving no match at all. ${ }^{5}$ Table 3 provides a comparison of the distribution of weekly hours of household production in the UT and the matched file. The tenth percentile is zero, so those ratios are undefined. The remaining percentile ratios are all relatively close, with the ratio of the median to the $25^{\text {th }}$ percentile being exactly equivalent. The Gini coefficient is extremely close, 0.5555 in the matched file, compared to 0.5545 in the UT. Table 4 breaks down the mean and median of the three categories of household production and the total in the matched file and the UT. ${ }^{6}$ We can see that for all four variables the difference in the matched and the source file's mean is small, with the largest difference in procurement, which is $7 \%$ (or twenty minutes) lower in the matched file than in the UT. Median total

\footnotetext{
${ }^{4}$ In a typical time use match (as in Masterson 2010), five variables are used, yielding a total of 32 matching cells. In this match, using seven strata variables, the number of matching cells in the first round was 575.

${ }^{5}$ The unmatched records are assigned the median values of hours of household production for their original matching cells.

${ }^{6}$ The three categories are care (childcare, eldercare, etc.), procurement (shopping, etc.), and core (cooking, cleaning, laundry, etc.).
} 
household production is $9 \%$ higher in the matched file, but this amounts to only 35 minutes per week.

Examination of the quality of the match within population subgroups shows generally good results. Figure 1 displays ratios of mean weekly hours of household production between the matched file and the UT for the seven strata variables. For almost all the categories, the average weekly hours in the matched file are within $10 \%$ of the UT. The one exception is for males, who have $26 \%$ higher weekly hours in the matched file, while females have $10 \%$ lower weekly hours. Table 5 has the actual numbers, and we can see that these large percentage differences represent relatively small differences in hours per week. In the case of sex, females have 2.8 fewer hours per week on average in the matched file, while males have 2.7 hours more. Notice that the ratios by category are well-reproduced in the matched file. The largest deviation is by sex, as we would expect given the differences in the averages for females and males. The extent to which the match file reproduces the distribution of weekly hours of household production within matching cells is demonstrated in Figure $2{ }^{7}$ We can see very little difference between the matched file and the UT. Thus the distribution of household production is wellpreserved in the matching process, even at this level of detail.

Overall, the quality of the match is very good. It has its limitations, especially in terms of sex of individuals. But the overall distribution is transferred with reasonable accuracy, and the distributions within even small subgroups, such as one adult with two children, is transferred with good precision.

\section{CHILE}

\section{Data and Alignment}

The source datasets for the time use match for the LIMTIP estimates for Chile are the 2006 CASEN and the 2007 EUT. We use individual records from the 2006 CASEN file, excluding those living in group quarters or in the Armed Forces. Since the EUT covers individuals aged 12 to 98 years old in Gran Santiago only, we discard younger and older individuals, as well as all individuals in areas outside of Gran Santiago from the CASEN file. This leaves a total of 28,039 individual records, representing 4,792,489 individuals when weighted. The EUT, unlike the UT

\footnotetext{
${ }^{7}$ For the sake of clarity of the plot, only the number of children and number of adults are used.
} 
in Argentina, covers all individuals in each household surveyed. Unfortunately, the EUT's only income variable is household income and that is categorical. There are also a small number of nonrespondents: 162 of 3,561 households (i.e., under 5\% nonresponse). Since household income category is a strata variable for this match, we multiply imputed the household income categories, creating five replicates for each record, resulting in 14,410 records representing 4,857,143 individuals.

The strata variables for this match are identical to those used in the Argentina match described above. Table 6 compares the distribution of individuals by these variables in the two datasets. We see that there are $1.9 \%$ fewer individuals in households without children in the time use sample than in the CASEN. Individuals in one- and two-adult households make up a greater share of those in the EUT (2\% and 7.2\%, respectively), while those in three-, four- and five-or-more adult households are more common in the CASEN. About 2.3\% fewer individuals are in households within the poverty band in the time use survey, compared to the overall survey, though the difference in the number of individuals in households with at least one nonemployed adult in the two surveys is less than $1 \%$. The distribution of individuals by household income is very different in the two surveys, with $13.6 \%$ more individuals in households in the middle category in the EUT than in the CASEN. Clearly this is due to the relatively poor income data in the EUT. ${ }^{8}$ The nonemployed are underrepresented in the UT relative to the $\mathrm{EAH}$ (3\%). The distribution of individuals by sex and employment status is very close in the two surveys, with less than $1 \%$ difference between the CASEN and the EUT for both variables. So, we have a very close alignment between the two surveys along five of the seven strata variables. We can expect that the match will be off by number of adults and household income, though only in the former can we readily predict the direction of the bias: With fewer individuals in one and two adult households represented in the CASEN, the household production weekly hours of the matched dataset are likely to be lower for those individuals than in the EUT, since many will be matched with individuals in the EUT from households with more adults, who will tend to have lower household production hours.

\section{Match QC}

Turning to the results of the match, we first look at the distribution of matched records by matching round in Table 7. The bulk of the matches, $66.8 \%$, occur in the first round. Again, this

\footnotetext{
${ }^{8}$ Multiply imputing the missing values did not significantly alter the distribution of household income in the EUT.
} 
is lower than in other time use matches, but similar to the result in the Argentina match. The rest of the records are matched over an additional twenty-three rounds, with $2.7 \%$ receiving no match at all. ${ }^{9}$ Table 8 provides a comparison of the distribution of weekly hours of household production in the EUT and the matched file. In the EUT, and the matched file, both the $25^{\text {th }}$ and the $10^{\text {th }}$ percentile are zero, so most of the ratios are undefined. The remaining percentile ratios are exactly the same in the matched file as in the EUT. The Gini coefficient is extremely close, 0.6152 in the matched file, compared to 0.6162 in the EUT. Note that the Gini coefficient is higher and the percentile values are lower in the case of Chile than in Argentina. This is due to the inclusion of 12 to 14 year olds, who tend to do less household production work, in the Chilean time use survey. Table 9 breaks down the mean and median of the three categories of household production and the total in the matched file and the EUT. We can see that for all four variables the difference in the matched and the source file's mean is small, less than $2 \%$ in all cases (with differences ranging from three to eight minutes per week). The median values are all carried over exactly.

Examination of the quality of the match within population subgroups shows generally good results. Figure 3 displays ratios of mean weekly hours of household production between the matched file and the EUT for the seven strata variables. For almost all the categories, the average weekly hours in the matched file are within $5 \%$ of those in the EUT. The exceptions are for individuals in households with three or more children (who have 5.8\% lower weekly hours of household production in the matched file), individuals in households outside of the poverty band (who have 5.3\% higher hours in the matched file), and males (who have 11.1\% higher weekly hours in the matched file), while females have 5.1\% lower weekly hours. Table 10 has the actual numbers, and we can see that these large percentage differences represent relatively small differences in hours per week. Individuals in households with three or more children have 1.4 hours fewer hours in the matched file than in the EUT, while those in households outside of the poverty band have just less than one hour higher weekly hours. In the case of sex, females have about 90 fewer minutes per week on average in the matched file, while males have 70 minutes more. Notice that the ratios by category are very well-reproduced in the matched file. The largest deviation is by sex, as we would expect given the differences in the averages for females and males. The medians are for the most part exactly carried over, but where they are

\footnotetext{
${ }^{9}$ As in the case of Argentina, the unmatched records are assigned the median values of hours of household production for their original matching cells.
} 
off it is by 3.5 hours. This is due to the nature of the time use data, which was collected for one day and recorded in half hour chunks of time.

The extent to which the match file reproduces the distribution of weekly hours of household production within the reference group is demonstrated in Figure $4 .{ }^{10}$ We can see very little difference between the matched file and the UT. In Table 11, we see the ratios of the average and median household total weekly hours of household production in the matched file to the EUT, for households in the reference group, broken down by number of children and number of adults. We can see that household production is well-preserved in the matching process, more so for the more populated cells (two-adult households, especially).

Overall, the quality of the match is very good. The overall distribution is transferred with good accuracy, and the distributions within even small subgroups, such as one adult with two children, is transferred with good precision.

\section{MEXICO}

\section{Data and Alignment}

The source datasets for the time use match for the LIMTIP estimates for Mexico are the 2008 ENIGH and the 2009 ENUT. We use individual records from the 2008 ENIGH file, excluding those living in group quarters or in the Armed Forces. The ENIGH has a number of missing values, which we replaced by the method of multiple imputation with hot-decking. ${ }^{11}$ This results in five replicates for each original record, for a total of 594,635, representing 106,866,209 individuals in Mexico. Since the time use data in the ENUT covers individuals aged 12 years of age and older, we discard younger individuals from the ENIGH file. This leaves 454,910 records, which represents 81,941,246 individuals when weighted. The ENUT file, from a nationally representative sample survey, contains records for all individuals, but time use data only for those 12 years of age and older, like Chile but unlike Argentina. The entire dataset contains 57,918 individual records, representing 109,047,562 individuals. Missing values in the

\footnotetext{
${ }^{10}$ For the sake of clarity of the plot, only the number of children and number of adults are used.

${ }^{11}$ The variables with missing values at the household level were indicators for homeownership, availability of water, type of fuel, number of rooms in the house, type of sewage removal, electricity, type of garbage removal, laundry, sink, water tank, gas tank, and heater. 4,815 of 29,468 household records had one or more missing values. The variables with missing values at the individual level were occupation and usual hours of work. 579 of 118,927 individual records had one or more missing values.
} 
base dataset were multiply imputed, resulting in five replicates for each individual record. ${ }^{12}$ This produces 289,590 records. Once those individuals aged 11 or less are dropped, 222,524 records remain, representing 84,679,672 individuals.

The strata variables for this match are identical to those used in the Argentina and Chile matches, with one addition: a geographical indicator for rural households. The latter is never dropped in the matching process, so all matches are within rural and urban segments of the recipient and donor datasets. ${ }^{13}$ Table 12 compares the distribution of individuals by these variables in the two datasets. Since both surveys are nationally representative and carried out within one year of each other, we can expect them to be well-aligned. About 2.6\% more individuals are in households with at least one nonemployed adult in the time use survey than in the income survey, while the difference in the number of individuals in households within the poverty band in the two surveys is $2.3 \%$. The distribution by household income is less close between the two surveys, with households in the ENIGH 4\% more likely to be in the second income category. The distribution of individuals by sex is very close in the two surveys, with females only slightly less common (0.3\%) in the ENIGH than in the ENUT. There are 3.5\% more employed individuals and $4.3 \%$ fewer inactive individuals in the ENIGH than in the ENUT. Finally, there is a small difference in the distribution of individuals by rural/urban status $(0.7 \%)$. So, as expected, we have a very close alignment between the two surveys along almost all eight strata variables.

\section{Match QC}

Turning to the results of the match, we first look to the distribution of matched records by matching round in Table 13. While the bulk of the matches, $80.3 \%$, occur in the first round, the remainder of the records required an additional 61 rounds of matching to completely exhaust individual records. Less than $1 \%$ of records received no match at all. ${ }^{14}$ This high number of matching rounds is unusual in our experience. The large number is due to the high number of records and strata variables. Table 14 provides a comparison of the distribution of weekly hours of household production in urban and rural areas in the ENUT and the matched file. The

\footnotetext{
${ }^{12}$ The variables with missing values at the household level were indicators for availability of water, type of fuel, number of rooms in the house, and type of sewage removal. 1,896 of 30,958 household records had one or more missing values. The variables with missing values at the individual level were marital status, age, wage income, transfer income, and other income. 1,681 of 57,918 individual records had one or more missing values.

${ }^{13}$ Rural is defined in the Mexican national poverty statistics as a municipality with fewer than 2,500 residents.

${ }^{14}$ The unmatched records are assigned the median values of hours of household production for their original matching cells.
} 
percentile ratios are all relatively close, with the ratios for urban areas being slightly higher, and those for rural areas slightly lower in each case. The Gini coefficients are also extremely close, with the urban Gini 0.13 points lower and the rural Gini 0.24 points higher than in the ENUT. Table 15 breaks down the mean and median of the three categories of household production and the total in the matched file and the ENUT. ${ }^{15}$ We can see that for all four variables the difference in the matched and the source file's mean and medians are small, with the largest differences in median rural care and total weekly hours of just over 1.5\% (about 15 and 20 minutes, respectively) higher in the matched file than in the ENUT.

Examination of the quality of the match within population subgroups shows generally good results. Figure 5a displays ratios of mean weekly hours of household production between the matched file and the ENUT for the seven strata variables in urban areas. In all cases, the average weekly hours in the matched file are within 5\% of the ENUT. In fact, with the exception of the lowest household income category which has $4.8 \%$ lower weekly hours in the matched file than in the ENUT, the averages for all subgroups are within 3\% of the ENUT average. The rural results (in Figure 5b) are slightly worse. Individuals in households without a nonemployed adult have $7.5 \%$ higher weekly hours of household production in the matched file than in the ENUT, employed individuals have 15\% higher weekly hours, and males have 8.1\% higher weekly hours. Tables 16 and 17 have the actual numbers, and we can see that even the larger percentage differences represent relatively small differences in hours per week. In the case of sex, rural females have 1.4 fewer hours per week on average in the matched file, while rural males have 1 hour more. The rural employed have three hours more household production per week in the matched file, the largest deviation by averages. Notice that the ratios by category are well-reproduced in the matched file, even for the categories with the largest average deviation. The largest difference is by sex in rural areas, as we would expect given the differences in the averages for rural females. The medians closely follow the patterns of the averages with similar differences in the rural areas by employment and sex. The extent to which the match file reproduces the distribution of total weekly hours of household production in households in the reference group is demonstrated in Figure 6. We can see there are some differences between the matched file and the ENUT. The upper tails are fatter for each of the cells in the reference groups. The ratios of the average and median household total weekly hours

\footnotetext{
${ }^{15}$ The three categories are care (childcare, eldercare, etc.), procurement (shopping, etc.), and core (cooking, cleaning, laundry, etc.).
} 
of production for the reference group in the matched file to the ENUT are presented in Table 18. In both rural and urban areas the largest differences are in one-adult households with children. These are the cells in the reference group which are the smallest, meaning they are likeliest to be off substantially, but also make less difference in terms of the target measure. Other cells have somewhat large differences, but most of these are households with three or more adults, which, again, are smaller cells. The largest difference among two-adult households is the average weekly hours for rural households with two adults and two children, among which households have $12 \%$ higher weekly hours of household production in the matched file than in the ENUT. Overall, the distribution of household production is well-preserved in the matching process, even at this level of detail.

Overall, the quality of the match is very good. It has its limitations, especially in terms of sex of individuals. But the overall distribution is transferred with very good accuracy. And the distributions within even small subgroups, such as one adult with two children, is transferred with good precision, compared with the other two countries. 


\section{REFERENCES}

Kum, Hyunsub and Thomas Neal Masterson. 2010. "Statistical matching using propensity scores: Theory and application to the analysis of the distribution of income and wealth." Journal of Economic and Social Measurement 35 (3): 177-196.

Masterson, Thomas. 2010. "Quality of Match for Statistical Matches Used in the 1992 and 2007 LIMEW Estimates for the United States.” Working Paper 618. Annandale-onHudson, NY: Levy Economics Institute of Bard College. 
TABLES

Table 1 Alignment of Strata Variables, Argentina

\begin{tabular}{|c|c|c|c|}
\hline & EAH 2005 & UT 2005 & Diff \\
\hline Number & $2,044,405$ & $2,128,750$ & $4.1 \%$ \\
\hline \multicolumn{4}{|c|}{ Number of children in household } \\
\hline 0 & $59.89 \%$ & $56.79 \%$ & $-3.1 \%$ \\
\hline 1 & $21.15 \%$ & $21.21 \%$ & $0.1 \%$ \\
\hline 2 & $12.86 \%$ & $14.51 \%$ & $1.7 \%$ \\
\hline $3+$ & $6.10 \%$ & $7.49 \%$ & $1.4 \%$ \\
\hline \multicolumn{4}{|c|}{ Number of adults in $\mathrm{HH}$} \\
\hline 1 & $13.00 \%$ & $12.05 \%$ & $-1.0 \%$ \\
\hline 2 & $45.59 \%$ & $45.09 \%$ & $-0.5 \%$ \\
\hline 3 & $23.29 \%$ & $26.48 \%$ & $3.2 \%$ \\
\hline 4 & $13.13 \%$ & $13.24 \%$ & $0.1 \%$ \\
\hline $5+$ & $4.99 \%$ & $3.14 \%$ & $-1.9 \%$ \\
\hline \multicolumn{4}{|c|}{ Presence of non-employed persons 15-74 in $\mathrm{HH} ?$} \\
\hline No & $25.82 \%$ & $22.98 \%$ & $-2.8 \%$ \\
\hline Yes & $74.18 \%$ & $77.02 \%$ & $2.8 \%$ \\
\hline \multicolumn{4}{|c|}{ Within Poverty band } \\
\hline No & $87.44 \%$ & $86.80 \%$ & $-0.6 \%$ \\
\hline Yes & $12.56 \%$ & $13.20 \%$ & $0.6 \%$ \\
\hline \multicolumn{4}{|c|}{ Household income category } \\
\hline$L T 1,000$ & $16.92 \%$ & $18.45 \%$ & $1.5 \%$ \\
\hline $1,000-1,599$ & $22.25 \%$ & $21.46 \%$ & $-0.8 \%$ \\
\hline $1,600-2,299$ & $20.70 \%$ & $22.14 \%$ & $1.4 \%$ \\
\hline $2,300-3,499$ & $20.16 \%$ & $18.45 \%$ & $-1.7 \%$ \\
\hline GE 3,500 & $19.97 \%$ & $19.49 \%$ & $-0.5 \%$ \\
\hline \multicolumn{4}{|l|}{ Employed? } \\
\hline No & $32.51 \%$ & $35.49 \%$ & $3.0 \%$ \\
\hline Yes & $67.49 \%$ & $64.51 \%$ & $-3.0 \%$ \\
\hline \multicolumn{4}{|c|}{ Sex of respondent, EAH 2005} \\
\hline Male & $46.32 \%$ & $44.89 \%$ & $-1.4 \%$ \\
\hline Female & $53.68 \%$ & $55.11 \%$ & $1.4 \%$ \\
\hline
\end{tabular}


Table 2 Distribution of Matched Records by Matching Round, Argentina

\begin{tabular}{|c|r|c|}
\hline Round & Number & Percentage \\
\hline $\mathbf{1}$ & $1,408,402$ & $68.9 \%$ \\
\hline $\mathbf{2}$ & 196,206 & $9.6 \%$ \\
\hline $\mathbf{3}$ & 57,115 & $2.8 \%$ \\
\hline $\mathbf{4}$ & 108,307 & $5.3 \%$ \\
\hline $\mathbf{5}$ & 39,850 & $1.9 \%$ \\
\hline $\mathbf{6}$ & 13,499 & $0.7 \%$ \\
\hline $\mathbf{7}$ & 24,833 & $1.2 \%$ \\
\hline $\mathbf{8}$ & 7,668 & $0.4 \%$ \\
\hline $\mathbf{9}$ & 4,992 & $0.2 \%$ \\
\hline $\mathbf{1 0}$ & 4,819 & $0.2 \%$ \\
\hline $\mathbf{1 1}$ & 46,477 & $2.3 \%$ \\
\hline $\mathbf{1 2}$ & 5,131 & $0.3 \%$ \\
\hline $\mathbf{1 3}$ & 3,366 & $0.2 \%$ \\
\hline $\mathbf{1 4}$ & 2,160 & $0.1 \%$ \\
\hline $\mathbf{1 5}$ & 2,872 & $0.1 \%$ \\
\hline $\mathbf{1 6}$ & 118,708 & $5.8 \%$ \\
\hline Total & $2,044,405$ & $100.0 \%$ \\
\hline
\end{tabular}

Table 3 Distribution of Weekly Hours of Household Production in UT 2005 and Matched File

\begin{tabular}{|l|c|c|c|c|c|c|c|}
\hline & p90/p10 & p90/p50 & p50/p10 & p75/p25 & p75/p50 & p50/p25 & Gini \\
\hline UT05 & & 4.092 & & 9.000 & 2.455 & 3.666 & 0.555 \\
\hline MATCH & & 3.952 & & 8.666 & 2.362 & 3.669 & 0.556 \\
\hline MATCH2 & & 3.952 & & 8.834 & 2.408 & 3.669 & 0.562 \\
\hline
\end{tabular}

Table 4 Comparison of Mean and Median Time Use Variables in Matched File to UT 2005

\begin{tabular}{|l|c|c|c|c|c|c|c|c|}
\hline & $\begin{array}{c}\text { Mean HH } \\
\text { Prod. }\end{array}$ & $\begin{array}{c}\text { Mean } \\
\text { Care }\end{array}$ & $\begin{array}{c}\text { Mean } \\
\text { Proc. }\end{array}$ & $\begin{array}{c}\text { Mean } \\
\text { Core }\end{array}$ & $\begin{array}{c}\text { Median } \\
\text { HH Prod. }\end{array}$ & $\begin{array}{c}\text { Median } \\
\text { Care }\end{array}$ & $\begin{array}{c}\text { Median } \\
\text { Proc. }\end{array}$ & $\begin{array}{c}\text { Median } \\
\text { Core }\end{array}$ \\
\hline UT05 & 11.90 & 3.44 & 4.91 & 20.25 & 6.42 & 0.00 & 0.00 & 12.83 \\
\hline MATCH & 11.71 & 3.32 & 4.57 & 19.79 & 7.00 & 0.00 & 0.00 & 12.84 \\
\hline Ratio & $98.40 \%$ & $96.51 \%$ & $93.08 \%$ & $97.73 \%$ & $109.03 \%$ & & & $100.08 \%$ \\
\hline
\end{tabular}


Table 5 Mean and Median Weekly Hours of Household Production by Strata Variable, UT 2005 and Matched File

\begin{tabular}{|c|c|c|c|c|c|c|}
\hline \multicolumn{4}{|c|}{ Mean values of HH Production (Weekly Hours) } & & & \\
\hline & UT05 & Match & Ratio & & & \\
\hline HH Production & 20.25 & 19.83 & $97.9 \%$ & & & \\
\hline Core & 11.90 & 11.71 & $98.4 \%$ & & & \\
\hline Procurement & 3.44 & 3.31 & $96.2 \%$ & & & \\
\hline Care & 4.91 & 4.66 & $94.9 \%$ & & & \\
\hline \multicolumn{4}{|c|}{ Distribution among population subgroups } & \multicolumn{3}{|c|}{ Ratio of Mean Values } \\
\hline & & & & & UT05 & Match \\
\hline \multicolumn{7}{|l|}{ Number of Children } \\
\hline 0 & 15.62 & 16.11 & $103.1 \%$ & $0 / 3+$ & 0.47 & 0.48 \\
\hline 1 & 24.14 & 22.70 & $94.0 \%$ & $1 / 3+$ & 0.73 & 0.68 \\
\hline 2 & 26.00 & 25.68 & $98.8 \%$ & $2 / 3+$ & 0.78 & 0.77 \\
\hline $3+$ & 33.20 & 33.35 & $100.5 \%$ & & & \\
\hline \multicolumn{7}{|l|}{ Number of Adults } \\
\hline 1 & 16.54 & 15.63 & $94.5 \%$ & $2 / 1$ & 1.36 & 1.41 \\
\hline 2 & 22.44 & 21.99 & $98.0 \%$ & $3+/ 1$ & 1.15 & 1.19 \\
\hline $3+$ & 18.99 & 18.66 & $98.3 \%$ & & & \\
\hline \multicolumn{7}{|c|}{ Within Poverty Band? } \\
\hline No & 18.92 & 18.73 & $99.0 \%$ & Yes/No & 1.53 & 1.45 \\
\hline Yes & 29.01 & 27.12 & $93.5 \%$ & & & \\
\hline \multicolumn{7}{|c|}{ Presence of Non-Employed Adult? } \\
\hline No & 11.46 & 12.36 & $107.9 \%$ & Yes/No & 2.00 & 1.81 \\
\hline Yes & 22.87 & 22.37 & $97.8 \%$ & & & \\
\hline Household Income & & & & & \multicolumn{2}{|c|}{ Over All } \\
\hline$L T 1,000$ & 24.05 & 23.08 & $96.0 \%$ & $L T 1,000$ & 1.19 & 1.16 \\
\hline $1,000-1,599$ & 22.22 & 21.18 & $95.3 \%$ & $1,000-1,599$ & 1.10 & 1.07 \\
\hline $1,600-2,299$ & 20.62 & 20.13 & $97.6 \%$ & $1,600-2,299$ & 1.02 & 1.02 \\
\hline $2,300-3,499$ & 16.91 & 18.47 & $109.2 \%$ & $2,300-3,499$ & 0.84 & 0.93 \\
\hline GE 3,500 & 17.22 & 16.41 & $95.3 \%$ & GE 3,500 & 0.85 & 0.83 \\
\hline \multicolumn{7}{|l|}{ Employed? } \\
\hline No & 27.97 & 25.96 & $92.8 \%$ & Yes/No & 0.57 & 0.65 \\
\hline Yes & 16.01 & 16.81 & $105.0 \%$ & & & \\
\hline \multicolumn{7}{|l|}{ Sex } \\
\hline Female & 28.35 & 25.62 & $90.4 \%$ & Female/Male & 2.75 & 1.97 \\
\hline Male & 10.31 & 13.03 & $126.4 \%$ & & & \\
\hline
\end{tabular}




\begin{tabular}{|c|c|c|c|c|c|c|}
\hline \multicolumn{4}{|c|}{ Median values of HH Production (Weekly Hours) } & & & \\
\hline & UT05 & Match & Ratio & & & \\
\hline HH Production & 12.83 & 12.84 & $100.1 \%$ & & & \\
\hline Core & 6.42 & 7.00 & $109.0 \%$ & & & \\
\hline Procurement & - & - & & & & \\
\hline Care & - & - & & & & \\
\hline \multicolumn{4}{|c|}{ Distribution among population subgroups } & \multicolumn{3}{|c|}{ Ratio of Median Values } \\
\hline & & & & & UT05 & Match \\
\hline \multicolumn{7}{|l|}{ Number of Children } \\
\hline 0 & 8.75 & 10.50 & $120.0 \%$ & $0 / 3+$ & 0.32 & 0.38 \\
\hline 1 & 18.09 & 16.33 & $90.3 \%$ & $1 / 3+$ & 0.66 & 0.58 \\
\hline 2 & 19.83 & 19.25 & $97.1 \%$ & $2 / 3+$ & 0.72 & 0.69 \\
\hline $3+$ & 27.42 & 28.00 & $102.1 \%$ & & & \\
\hline \multicolumn{7}{|l|}{ Number of Adults } \\
\hline 1 & 11.67 & 11.67 & $100.0 \%$ & $2 / 1$ & 1.20 & 1.20 \\
\hline 2 & 14.00 & 14.00 & $100.0 \%$ & $3+/ 1$ & 0.90 & 1.00 \\
\hline $3+$ & 10.50 & 11.67 & $111.1 \%$ & & & \\
\hline \multicolumn{7}{|c|}{ Within Poverty Band? } \\
\hline No & 12.25 & 12.25 & $100.0 \%$ & Yes/No & 1.71 & 1.38 \\
\hline Yes & 21.00 & 16.92 & $80.6 \%$ & & & \\
\hline \multicolumn{7}{|c|}{ Presence of Non-Employed Adult? } \\
\hline No & 7.00 & 7.00 & $100.0 \%$ & Yes/No & 2.25 & 2.25 \\
\hline Yes & 15.75 & 15.75 & $100.0 \%$ & & & \\
\hline Household Income & & & & & \multicolumn{2}{|c|}{ Over All } \\
\hline$L T 1,000$ & 15.75 & 15.75 & $100.0 \%$ & $L T 1,000$ & 1.23 & 1.23 \\
\hline $1,000-1,599$ & 15.75 & 14.00 & $88.9 \%$ & $1,000-1,599$ & 1.23 & 1.09 \\
\hline $1,600-2,299$ & 14.58 & 13.42 & $92.0 \%$ & $1,600-2,299$ & 1.14 & 1.05 \\
\hline $2,300-3,499$ & 10.50 & 11.67 & $111.1 \%$ & $2,300-3,499$ & 0.82 & 0.91 \\
\hline GE 3,500 & 9.92 & 10.50 & $105.8 \%$ & GE 3,500 & 0.77 & 0.82 \\
\hline \multicolumn{7}{|l|}{ Employed? } \\
\hline No & 23.92 & 18.67 & $78.1 \%$ & Yes/No & 0.44 & 0.56 \\
\hline Yes & 10.50 & 10.50 & $100.0 \%$ & & & \\
\hline \multicolumn{7}{|l|}{ Sex } \\
\hline Female & 24.50 & 19.25 & $78.6 \%$ & Female/Male & 5.25 & 2.75 \\
\hline Male & 4.67 & 7.00 & $149.9 \%$ & & & \\
\hline
\end{tabular}


Table 6 Alignment of Strata Variables, Chile

\begin{tabular}{|c|c|c|c|}
\hline & CASEN & EUT & Diff \\
\hline individuals & $4,792,489$ & $4,857,105$ & $1.3 \%$ \\
\hline \multicolumn{4}{|c|}{ Number of children in household } \\
\hline 0 & $33.70 \%$ & $35.55 \%$ & $1.9 \%$ \\
\hline 1 & $27.75 \%$ & $28.27 \%$ & $0.5 \%$ \\
\hline 2 & $22.75 \%$ & $22.46 \%$ & $-0.3 \%$ \\
\hline 3 & $11.18 \%$ & $9.55 \%$ & $-1.6 \%$ \\
\hline $4+$ & $4.63 \%$ & $4.17 \%$ & $-0.5 \%$ \\
\hline \multicolumn{4}{|c|}{ Number of adults in household } \\
\hline 1 & $4.89 \%$ & $6.87 \%$ & $2.0 \%$ \\
\hline 2 & $32.80 \%$ & $40.01 \%$ & $7.2 \%$ \\
\hline 3 & $28.58 \%$ & $26.27 \%$ & $-2.3 \%$ \\
\hline 4 & $19.81 \%$ & $18.01 \%$ & $-1.8 \%$ \\
\hline $5+$ & $13.92 \%$ & $8.85 \%$ & $-5.1 \%$ \\
\hline \multicolumn{4}{|c|}{ Is the household within the poverty band? } \\
\hline No & $82.01 \%$ & $84.27 \%$ & $2.3 \%$ \\
\hline Yes & $17.99 \%$ & $15.73 \%$ & $-2.3 \%$ \\
\hline \multicolumn{4}{|c|}{ Is there a non-working adult in $\mathrm{HH}$ ? } \\
\hline No & $26.65 \%$ & $26.19 \%$ & $-0.5 \%$ \\
\hline Yes & 73.35\% & $73.81 \%$ & $0.5 \%$ \\
\hline \multicolumn{4}{|c|}{ Household income category } \\
\hline LE 144,000 & $6.86 \%$ & $5.99 \%$ & $-0.9 \%$ \\
\hline $144,001-250,000$ & $11.66 \%$ & $4.55 \%$ & $-7.1 \%$ \\
\hline $250,001-500,000$ & $28.33 \%$ & $41.94 \%$ & $13.6 \%$ \\
\hline $500,001-1,000,000$ & $28.33 \%$ & $27.62 \%$ & $-0.7 \%$ \\
\hline GT $1,000,000$ & $24.81 \%$ & $19.90 \%$ & $-4.9 \%$ \\
\hline \multicolumn{4}{|l|}{ Labor force status } \\
\hline Employed & $53.69 \%$ & $53.85 \%$ & $0.2 \%$ \\
\hline Unemployed & $4.07 \%$ & $4.46 \%$ & $0.4 \%$ \\
\hline Inactive & $42.24 \%$ & $41.69 \%$ & $-0.6 \%$ \\
\hline \multicolumn{4}{|l|}{ Sex of respondent } \\
\hline Female & $52.36 \%$ & $51.94 \%$ & $-0.4 \%$ \\
\hline Male & $47.64 \%$ & $48.06 \%$ & $0.4 \%$ \\
\hline
\end{tabular}


Table 7 Distribution of Matched Records by Matching Round, Chile

\begin{tabular}{|c|r|c|c|}
\hline $\begin{array}{c}\text { Matching } \\
\text { Round }\end{array}$ & $\begin{array}{c}\text { Records } \\
\text { Matched }\end{array}$ & Percentage & $\begin{array}{c}\text { Cumulative } \\
\text { Percentage }\end{array}$ \\
\hline $\mathbf{1}$ & $3,199,722$ & $66.8 \%$ & 66.8 \\
\hline $\mathbf{2}$ & 232,383 & $4.8 \%$ & 71.6 \\
\hline $\mathbf{3}$ & 76,303 & $1.6 \%$ & 73.2 \\
\hline $\mathbf{4}$ & 442,051 & $9.2 \%$ & 82.4 \\
\hline $\mathbf{5}$ & 12,859 & $0.3 \%$ & 82.7 \\
\hline $\mathbf{6}$ & 64,310 & $1.3 \%$ & 84.0 \\
\hline $\mathbf{7}$ & 12,723 & $0.3 \%$ & 84.3 \\
\hline $\mathbf{8}$ & 20,621 & $0.4 \%$ & 84.7 \\
\hline $\mathbf{9}$ & 20,338 & $0.4 \%$ & 85.2 \\
\hline $\mathbf{1 0}$ & 144,445 & $3.0 \%$ & 88.2 \\
\hline $\mathbf{1 1}$ & 40,367 & $0.8 \%$ & 89.0 \\
\hline $\mathbf{1 2}$ & 20,173 & $0.4 \%$ & 89.4 \\
\hline $\mathbf{1 3}$ & 2,421 & $0.1 \%$ & 89.5 \\
\hline $\mathbf{1 4}$ & 114,634 & $2.4 \%$ & 91.9 \\
\hline $\mathbf{1 5}$ & 16,085 & $0.3 \%$ & 92.2 \\
\hline $\mathbf{1 6}$ & 102,113 & $2.1 \%$ & 94.3 \\
\hline $\mathbf{1 7}$ & 13,413 & $0.3 \%$ & 94.6 \\
\hline $\mathbf{1 8}$ & 7,688 & $0.2 \%$ & 94.8 \\
\hline $\mathbf{1 9}$ & 13,843 & $0.3 \%$ & 95.1 \\
\hline $\mathbf{2 0}$ & 6,867 & $0.1 \%$ & 95.2 \\
\hline $\mathbf{2 1}$ & 46,606 & $1.0 \%$ & 96.2 \\
\hline $\mathbf{2 2}$ & 20,017 & $0.4 \%$ & 96.6 \\
\hline $\mathbf{2 3}$ & 7,944 & $0.2 \%$ & 96.8 \\
\hline $\mathbf{2 4}$ & 26,661 & $0.6 \%$ & 97.3 \\
\hline $\mathbf{2 5}$ & 127,902 & $2.7 \%$ & 100.0 \\
\hline $\mathbf{T o t a l}$ & $4,792,489$ & & \\
\hline & & & \\
\hline
\end{tabular}

Table 8 Distribution of Weekly Hours of Household Production in EUT and Matched File

\begin{tabular}{|l|c|c|c|c|c|c|c|}
\hline & p90/p10 & p90/p50 & p50/p10 & p75/p25 & p75/p50 & p50/p25 & Gini \\
\hline EUT07 & & 5.33 & &. & 3.00 &. & 0.6162 \\
\hline MATCH & & 5.33 & &. & 3.00 &. & 0.6152 \\
\hline
\end{tabular}

Table 9 Comparison of Mean and Median Time Use Variables in 2007 EUT and Matched File

\begin{tabular}{|l|c|c|c|c|c|c|c|c|}
\hline & $\begin{array}{c}\text { Mean } \\
\text { Care }\end{array}$ & $\begin{array}{c}\text { Mean } \\
\text { Proc. }\end{array}$ & $\begin{array}{c}\text { Mean } \\
\text { Core }\end{array}$ & $\begin{array}{c}\text { Mean HH } \\
\text { Prod. }\end{array}$ & $\begin{array}{c}\text { Median } \\
\text { Care }\end{array}$ & $\begin{array}{c}\text { Median } \\
\text { Proc. }\end{array}$ & $\begin{array}{c}\text { Median } \\
\text { Core }\end{array}$ & $\begin{array}{c}\text { Median } \\
\text { HH Prod. }\end{array}$ \\
\hline EUT & 13.16 & 3.02 & 3.70 & 19.88 & 7.00 & 0.00 & 0.00 & 10.50 \\
\hline MATCH & 13.04 & 2.97 & 3.64 & 19.74 & 7.00 & 0.00 & 0.00 & 10.50 \\
\hline Ratio & $99.09 \%$ & $98.34 \%$ & $98.38 \%$ & $99.30 \%$ & $100.00 \%$ & & & $100.00 \%$ \\
\hline
\end{tabular}


Table 10 Mean and Median Household Production Weekly Hours, 2007 EUT and Matched File

\begin{tabular}{|c|c|c|c|c|c|c|}
\hline \multicolumn{4}{|c|}{ Mean values of HH Production (Weekly Hours) } & & & \\
\hline & UT05 & Match & Ratio & & & \\
\hline HH Production & 19.88 & 19.74 & $99.3 \%$ & & & \\
\hline Core & 13.16 & 13.04 & $99.1 \%$ & & & \\
\hline Procurement & 3.02 & 2.97 & $98.3 \%$ & & & \\
\hline Care & 3.70 & 3.64 & $98.4 \%$ & & & \\
\hline \multicolumn{4}{|c|}{ Distribution among population subgroups } & \multicolumn{3}{|c|}{ Ratio of Mean Values } \\
\hline & & & & & UT05 & Match \\
\hline \multicolumn{7}{|l|}{ Number of Children } \\
\hline 0 & 17.30 & 17.17 & $99.2 \%$ & $0 / 3+$ & 0.73 & 0.76 \\
\hline 1 & 19.37 & 19.54 & $100.9 \%$ & $1 / 3+$ & 0.81 & 0.87 \\
\hline 2 & 22.18 & 21.91 & $98.8 \%$ & $2 / 3+$ & 0.93 & 0.98 \\
\hline $3+$ & 23.82 & 22.45 & $94.2 \%$ & & & \\
\hline \multicolumn{7}{|l|}{ Number of Adults } \\
\hline 1 & 21.35 & 21.90 & $102.6 \%$ & $2 / 1$ & 1.00 & 0.96 \\
\hline 2 & 21.45 & 21.03 & $98.0 \%$ & $3+/ 1$ & 0.87 & 0.84 \\
\hline $3+$ & 18.50 & 18.48 & $99.9 \%$ & & & \\
\hline \multicolumn{7}{|c|}{ Within Poverty Band? } \\
\hline No & 17.47 & 18.40 & $105.3 \%$ & Yes/No & 1.19 & 1.10 \\
\hline Yes & 20.73 & 20.22 & $97.5 \%$ & & & \\
\hline \multicolumn{7}{|c|}{ Presence of Non-Employed Adult? } \\
\hline No & 19.42 & 19.33 & $99.5 \%$ & Yes/No & 1.15 & 1.12 \\
\hline Yes & 22.32 & 21.59 & $96.7 \%$ & & & \\
\hline Household Income & & & & & \multicolumn{2}{|c|}{ Over All } \\
\hline$L T 1,000$ & 22.67 & 21.78 & $96.1 \%$ & $L T 1,000$ & 1.14 & 1.10 \\
\hline $1,000-1,599$ & 21.99 & 21.57 & $98.1 \%$ & $1,000-1,599$ & 1.11 & 1.09 \\
\hline $1,600-2,299$ & 21.25 & 21.60 & $101.6 \%$ & $1,600-2,299$ & 1.07 & 1.09 \\
\hline $2,300-3,499$ & 18.77 & 18.64 & $99.3 \%$ & $2,300-3,499$ & 0.94 & 0.94 \\
\hline GE 3,500 & 17.21 & 17.45 & $101.4 \%$ & GE 3,500 & 0.87 & 0.88 \\
\hline \multicolumn{7}{|l|}{ Employed? } \\
\hline No & 25.67 & 25.02 & $97.5 \%$ & Yes/No & 0.58 & 0.61 \\
\hline Yes & 14.92 & 15.19 & $101.8 \%$ & & & \\
\hline \multicolumn{7}{|l|}{ Sex } \\
\hline Male & 9.97 & 11.14 & $111.7 \%$ & Female/Male & 0.34 & 0.40 \\
\hline Female & 29.04 & 27.56 & $94.9 \%$ & & & \\
\hline
\end{tabular}




\begin{tabular}{|c|c|c|c|c|c|c|}
\hline \multicolumn{4}{|c|}{ Median values of HH Production (Weekly Hours) } & & & \\
\hline & UT05 & Match & Ratio & & & \\
\hline HH Production & 10.50 & 10.50 & $100.0 \%$ & & & \\
\hline Core & 7.00 & 7.00 & $100.0 \%$ & & & \\
\hline Procurement & - & - & & & & \\
\hline Care & - & - & & & & \\
\hline \multicolumn{4}{|c|}{ Distribution among population subgroups } & \multicolumn{3}{|c|}{ Ratio of Median Values } \\
\hline & & & & & UT05 & Match \\
\hline \multicolumn{7}{|l|}{ Number of Children } \\
\hline 0 & 10.50 & 7.00 & $66.7 \%$ & $0 / 3+$ & 1.00 & 0.67 \\
\hline 1 & 10.50 & 10.50 & $100.0 \%$ & $1 / 3+$ & 1.00 & 1.00 \\
\hline 2 & 14.00 & 14.00 & $100.0 \%$ & $2 / 3+$ & 1.33 & 1.33 \\
\hline $3+$ & 10.50 & 10.50 & $100.0 \%$ & & & \\
\hline \multicolumn{7}{|l|}{ Number of Adults } \\
\hline 1 & 14.00 & 17.50 & $125.0 \%$ & $2 / 1$ & 0.75 & 0.60 \\
\hline 2 & 10.50 & 10.50 & $100.0 \%$ & $3+/ 1$ & 0.50 & 0.40 \\
\hline $3+$ & 7.00 & 7.00 & $100.0 \%$ & & & \\
\hline \multicolumn{7}{|c|}{ Within Poverty Band? } \\
\hline No & 10.50 & 10.50 & $100.0 \%$ & Yes/No & 1.00 & 1.00 \\
\hline Yes & 10.50 & 10.50 & $100.0 \%$ & & & \\
\hline \multicolumn{7}{|c|}{ Presence of Non-Employed Adult? } \\
\hline No & 10.50 & 10.50 & $100.0 \%$ & Yes/No & 1.33 & 1.33 \\
\hline Yes & 14.00 & 14.00 & $100.0 \%$ & & & \\
\hline Household Income & & & & & \multicolumn{2}{|c|}{ Over All } \\
\hline$L T 1,000$ & 17.50 & 17.50 & $100.0 \%$ & $L T 1,000$ & 1.67 & 1.67 \\
\hline $1,000-1,599$ & 17.50 & 14.00 & $80.0 \%$ & $1,000-1,599$ & 1.67 & 1.33 \\
\hline $1,600-2,299$ & 14.00 & 14.00 & $100.0 \%$ & $1,600-2,299$ & 1.33 & 1.33 \\
\hline $2,300-3,499$ & 7.00 & 7.00 & $100.0 \%$ & $2,300-3,499$ & 0.67 & 0.67 \\
\hline GE 3,500 & 7.00 & 10.50 & $150.0 \%$ & GE 3,500 & 0.67 & 1.00 \\
\hline \multicolumn{7}{|l|}{ Employed? } \\
\hline No & 17.50 & 17.50 & $100.0 \%$ & Yes/No & 0.20 & 0.40 \\
\hline Yes & 3.50 & 7.00 & $200.0 \%$ & & & \\
\hline \multicolumn{7}{|l|}{ Sex } \\
\hline Male & 0.00 & 0.00 & & Female/Male & 0.00 & 0.00 \\
\hline Female & 24.50 & 21.00 & $85.7 \%$ & & & \\
\hline
\end{tabular}


Table 11 Household Production Weekly Hours for Households in Reference Group, Ratio of Matched File to EUT 2007

\begin{tabular}{|c|c|c|c|c|c|c|}
\hline \multirow{2}{*}{\multicolumn{2}{|c|}{ Number of Adults }} & \multicolumn{5}{|c|}{ Number of Children } \\
\hline & & 0 & 1 & 2 & $3+$ & $\overline{\text { All }}$ \\
\hline \multirow{2}{*}{1} & Mean & $82.8 \%$ & $57.1 \%$ & $81.0 \%$ & $107.8 \%$ & $75.5 \%$ \\
\hline & Median & $90.9 \%$ & $77.8 \%$ & $0.0 \%$ & $90.2 \%$ & $80.0 \%$ \\
\hline \multirow{2}{*}{2} & Mean & $87.8 \%$ & $75.0 \%$ & $83.7 \%$ & $97.8 \%$ & $84.4 \%$ \\
\hline & \begin{tabular}{|l|} 
Median \\
\end{tabular} & $80.0 \%$ & $94.1 \%$ & $70.0 \%$ & $73.9 \%$ & $78.9 \%$ \\
\hline \multirow{2}{*}{$3+$} & Mean & $95.5 \%$ & $94.3 \%$ & $105.3 \%$ & $86.1 \%$ & $94.4 \%$ \\
\hline & Median & $94.4 \%$ & $95.7 \%$ & $126.1 \%$ & $78.6 \%$ & $100.0 \%$ \\
\hline
\end{tabular}


Table 12 Alignment of Strata Variables, Mexico

\begin{tabular}{|c|c|c|c|}
\hline & ENUT 2009 & ENIGH 2008 & diff \\
\hline individuals & $84,676,629$ & $81,945,375$ & $-3.2 \%$ \\
\hline \multicolumn{4}{|c|}{ Number of children in household } \\
\hline 0 & $45.2 \%$ & $43.2 \%$ & $-1.9 \%$ \\
\hline 1 & $19.5 \%$ & $18.8 \%$ & $-0.7 \%$ \\
\hline 2 & $19.5 \%$ & $19.1 \%$ & $-0.5 \%$ \\
\hline 3 & $10.1 \%$ & $11.8 \%$ & $1.7 \%$ \\
\hline $4+$ & $5.8 \%$ & $7.1 \%$ & $1.4 \%$ \\
\hline \multicolumn{4}{|c|}{ Number of adults in household } \\
\hline 1 & $5.9 \%$ & $5.6 \%$ & $-0.3 \%$ \\
\hline 2 & $35.4 \%$ & $36.5 \%$ & $1.1 \%$ \\
\hline 3 & $19.7 \%$ & $19.3 \%$ & $-0.4 \%$ \\
\hline 4 & $14.5 \%$ & $14.6 \%$ & $0.1 \%$ \\
\hline 5 & $9.6 \%$ & $8.4 \%$ & $-1.3 \%$ \\
\hline 6 & $6.0 \%$ & $6.4 \%$ & $0.4 \%$ \\
\hline 7 & $3.7 \%$ & $3.7 \%$ & $0.0 \%$ \\
\hline 8 & $2.4 \%$ & $2.8 \%$ & $0.4 \%$ \\
\hline 9 & $1.4 \%$ & $1.3 \%$ & $-0.1 \%$ \\
\hline $10+$ & $1.4 \%$ & $1.5 \%$ & $0.0 \%$ \\
\hline \multicolumn{4}{|c|}{ Presence of non-employed adult in household? } \\
\hline No & $22.1 \%$ & $24.7 \%$ & $2.6 \%$ \\
\hline Yes & $77.9 \%$ & $75.3 \%$ & $-2.6 \%$ \\
\hline \multicolumn{4}{|c|}{ Within poverty band for time use estimation? } \\
\hline No & $68.9 \%$ & $66.7 \%$ & $-2.3 \%$ \\
\hline Yes & $31.1 \%$ & $33.3 \%$ & $2.3 \%$ \\
\hline \multicolumn{4}{|c|}{ Household income category } \\
\hline Less than 2500 & $14.7 \%$ & $12.1 \%$ & $-2.6 \%$ \\
\hline 2500 to 4999 & $16.4 \%$ & $20.4 \%$ & $4.0 \%$ \\
\hline 5000 to 7499 & $16.2 \%$ & $17.2 \%$ & $1.1 \%$ \\
\hline 7500 to 14999 & $28.4 \%$ & $27.6 \%$ & $-0.8 \%$ \\
\hline 15000 or more & $24.4 \%$ & $22.7 \%$ & $-1.7 \%$ \\
\hline \multicolumn{4}{|c|}{ Sex of respondent } \\
\hline Female & $52.6 \%$ & $52.3 \%$ & $-0.3 \%$ \\
\hline Male & $47.5 \%$ & $47.7 \%$ & $0.3 \%$ \\
\hline \multicolumn{4}{|l|}{ Labor force status } \\
\hline Employed & $49.6 \%$ & $53.1 \%$ & $3.5 \%$ \\
\hline Unemployed & $1.8 \%$ & $2.6 \%$ & $0.8 \%$ \\
\hline Inactive & $48.6 \%$ & $44.3 \%$ & $-4.3 \%$ \\
\hline \multicolumn{4}{|c|}{ Rural household? } \\
\hline No & $79.5 \%$ & $78.8 \%$ & $-0.7 \%$ \\
\hline Yes & $20.5 \%$ & $21.2 \%$ & $0.7 \%$ \\
\hline
\end{tabular}


Table 13 Distribution of Matched Records by Matching Round, Mexico Match

\begin{tabular}{|c|r|r|r|r|r|r|r|}
\hline $\begin{array}{c}\text { Matching } \\
\text { Round }\end{array}$ & $\begin{array}{c}\text { Records } \\
\text { Matched }\end{array}$ & Percentage & $\begin{array}{c}\text { Cumulative } \\
\text { Percentage }\end{array}$ & $\begin{array}{c}\text { Matching } \\
\text { Round }\end{array}$ & $\begin{array}{c}\text { Records } \\
\text { Matched }\end{array}$ & Percentage & $\begin{array}{c}\text { Cumulative } \\
\text { Percentage }\end{array}$ \\
\hline $\mathbf{1}$ & $65,795,628$ & $80.3 \%$ & $80.3 \%$ & $\mathbf{3 3}$ & 6,944 & $0.0 \%$ & $97.0 \%$ \\
\hline $\mathbf{2}$ & $2,983,564$ & $3.6 \%$ & $83.9 \%$ & $\mathbf{3 4}$ & 9,931 & $0.0 \%$ & $97.0 \%$ \\
\hline $\mathbf{3}$ & $1,023,700$ & $1.2 \%$ & $85.2 \%$ & $\mathbf{3 5}$ & 28,308 & $0.0 \%$ & $97.0 \%$ \\
\hline $\mathbf{4}$ & $4,590,113$ & $5.6 \%$ & $90.8 \%$ & $\mathbf{3 6}$ & 228,473 & $0.3 \%$ & $97.3 \%$ \\
\hline $\mathbf{5}$ & 156,005 & $0.2 \%$ & $91.0 \%$ & $\mathbf{3 7}$ & 31,713 & $0.0 \%$ & $97.4 \%$ \\
\hline $\mathbf{6}$ & 496,904 & $0.6 \%$ & $91.6 \%$ & $\mathbf{3 8}$ & 34,885 & $0.0 \%$ & $97.4 \%$ \\
\hline $\mathbf{7}$ & 63,297 & $0.1 \%$ & $91.7 \%$ & $\mathbf{3 9}$ & 12,074 & $0.0 \%$ & $97.4 \%$ \\
\hline $\mathbf{8}$ & 241,519 & $0.3 \%$ & $92.0 \%$ & $\mathbf{4 0}$ & 103,770 & $0.1 \%$ & $97.5 \%$ \\
\hline $\mathbf{9}$ & 675,121 & $0.8 \%$ & $92.8 \%$ & $\mathbf{4 1}$ & 75,976 & $0.1 \%$ & $97.6 \%$ \\
\hline $\mathbf{1 0}$ & 342,831 & $0.4 \%$ & $93.2 \%$ & $\mathbf{4 2}$ & 19,539 & $0.0 \%$ & $97.7 \%$ \\
\hline $\mathbf{1 1}$ & 90,381 & $0.1 \%$ & $93.3 \%$ & $\mathbf{4 3}$ & 12,484 & $0.0 \%$ & $97.7 \%$ \\
\hline $\mathbf{1 2}$ & 233,351 & $0.3 \%$ & $93.6 \%$ & $\mathbf{4 4}$ & 30,291 & $0.0 \%$ & $97.7 \%$ \\
\hline $\mathbf{1 3}$ & 34,068 & $0.0 \%$ & $93.6 \%$ & $\mathbf{4 5}$ & 55,343 & $0.1 \%$ & $97.8 \%$ \\
\hline $\mathbf{1 4}$ & 22,281 & $0.0 \%$ & $93.7 \%$ & $\mathbf{4 6}$ & 832 & $0.0 \%$ & $97.8 \%$ \\
\hline $\mathbf{1 5}$ & 10,257 & $0.0 \%$ & $93.7 \%$ & $\mathbf{4 7}$ & 33 & $0.0 \%$ & $97.8 \%$ \\
\hline $\mathbf{1 6}$ & 10,854 & $0.0 \%$ & $93.7 \%$ & $\mathbf{4 8}$ & 3,152 & $0.0 \%$ & $97.8 \%$ \\
\hline $\mathbf{1 7}$ & $1,307,221$ & $1.6 \%$ & $95.3 \%$ & $\mathbf{4 9}$ & 2,768 & $0.0 \%$ & $97.8 \%$ \\
\hline $\mathbf{1 8}$ & 82,304 & $0.1 \%$ & $95.4 \%$ & $\mathbf{5 0}$ & 79,576 & $0.1 \%$ & $97.9 \%$ \\
\hline $\mathbf{1 9}$ & 52,877 & $0.1 \%$ & $95.4 \%$ & $\mathbf{5 1}$ & 42,172 & $0.1 \%$ & $97.9 \%$ \\
\hline $\mathbf{2 0}$ & 1,758 & $0.0 \%$ & $95.4 \%$ & $\mathbf{5 2}$ & 42,826 & $0.1 \%$ & $98.0 \%$ \\
\hline $\mathbf{2 1}$ & 25,433 & $0.0 \%$ & $95.5 \%$ & $\mathbf{5 3}$ & 171,961 & $0.2 \%$ & $98.2 \%$ \\
\hline $\mathbf{2 2}$ & 32,047 & $0.0 \%$ & $95.5 \%$ & $\mathbf{5 4}$ & 6,968 & $0.0 \%$ & $98.2 \%$ \\
\hline $\mathbf{2 3}$ & 3,765 & $0.0 \%$ & $95.5 \%$ & $\mathbf{5 5}$ & 41,902 & $0.1 \%$ & $98.3 \%$ \\
\hline $\mathbf{2 4}$ & 109,684 & $0.1 \%$ & $95.7 \%$ & $\mathbf{5 6}$ & 25,595 & $0.0 \%$ & $98.3 \%$ \\
\hline $\mathbf{2 5}$ & 4,643 & $0.0 \%$ & $95.7 \%$ & $\mathbf{5 7}$ & 38,067 & $0.0 \%$ & $98.3 \%$ \\
\hline $\mathbf{2 6}$ & 36,383 & $0.0 \%$ & $95.7 \%$ & $\mathbf{5 8}$ & 93,886 & $0.1 \%$ & $98.4 \%$ \\
\hline $\mathbf{2 7}$ & 50,289 & $0.1 \%$ & $95.8 \%$ & $\mathbf{5 9}$ & 5,103 & $0.0 \%$ & $98.5 \%$ \\
\hline $\mathbf{2 8}$ & 210,461 & $0.3 \%$ & $96.0 \%$ & $\mathbf{6 0}$ & 114,463 & $0.1 \%$ & $98.6 \%$ \\
\hline $\mathbf{2 9}$ & 4,629 & $0.0 \%$ & $96.0 \%$ & $\mathbf{6 1}$ & 473,449 & $0.6 \%$ & $99.2 \%$ \\
\hline $\mathbf{3 0}$ & 177,398 & $0.2 \%$ & $96.2 \%$ & $\mathbf{6 2}$ & 358,417 & $0.4 \%$ & $99.6 \%$ \\
\hline $\mathbf{3 1}$ & 136,605 & $0.2 \%$ & $96.4 \%$ & $\mathbf{6 3}$ & 322,389 & $0.4 \%$ & $100.0 \%$ \\
\hline $\mathbf{3 2}$ & 466,714 & $0.6 \%$ & $97.0 \%$ & $\mathbf{T o t a l}$ & $81,945,375$ & & \\
\hline
\end{tabular}

Table 14 Distribution of Household Production in 2009 ENUT and Matched File

\begin{tabular}{|c|l|c|c|c|c|c|c|c|}
\hline \multicolumn{2}{|c|}{} & p90/p10 & p90/p50 & p50/p10 & p75/p25 & p75/p50 & p50/p25 & Gini \\
\hline \multirow{2}{*}{ ENUT09 } & Urban & 21.848 & 3.538 & 6.175 & 5.959 & 2.296 & 2.596 & 0.4935 \\
\cline { 2 - 9 } & Rural & 22.933 & 3.161 & 7.255 & 6.276 & 2.250 & 2.790 & 0.4762 \\
\hline \multirow{2}{*}{ Match } & Urban & 22.108 & 3.557 & 6.215 & 6.017 & 2.307 & 2.608 & 0.4948 \\
\cline { 2 - 9 } & Rural & 22.444 & 3.135 & 7.159 & 6.061 & 2.201 & 2.754 & 0.4739 \\
\hline
\end{tabular}


Table 15 Comparison of Mean and Median Time Use Variables in 2009 ENUT and Matched File

\begin{tabular}{|c|c|c|c|c|c|c|c|c|c|c|c|}
\hline & & $\begin{array}{l}\text { Mean } \\
\text { Care }\end{array}$ & $\begin{array}{l}\text { Mean } \\
\text { Proc. }\end{array}$ & $\begin{array}{l}\text { Mean } \\
\text { Core }\end{array}$ & $\begin{array}{c}\text { Mean } \\
\text { Personal }\end{array}$ & $\begin{array}{l}\text { Mean HH } \\
\text { Prod. }\end{array}$ & $\begin{array}{l}\text { Median } \\
\text { Care }\end{array}$ & $\begin{array}{c}\text { Median } \\
\text { Proc. }\end{array}$ & $\begin{array}{l}\text { Median } \\
\text { Core }\end{array}$ & $\begin{array}{l}\text { Median } \\
\text { Personal }\end{array}$ & $\begin{array}{l}\text { Median } \\
\text { HH Prod. }\end{array}$ \\
\hline ENUT09 & Urban & 17.93 & 7.59 & 1.50 & 75.31 & 27.02 & 11.21 & 0.00 & 0.89 & 73.11 & 17.26 \\
\hline ENUT09 & Rural & 23.18 & 8.17 & 1.19 & 81.67 & 32.54 & 15.20 & 0.00 & 0.00 & 78.84 & 21.58 \\
\hline MATCH & Urban & 17.88 & 7.65 & 1.49 & 75.15 & 27.02 & 11.13 & 0.00 & 0.89 & 73.02 & 17.22 \\
\hline MATCH & Rural & 23.08 & 7.99 & 1.20 & 81.80 & 32.34 & 15.44 & 0.00 & 0.00 & 79.00 & 21.91 \\
\hline Ratio & Urban & $99.72 \%$ & $100.79 \%$ & $99.33 \%$ & $99.79 \%$ & $100.00 \%$ & $99.29 \%$ & & $100.00 \%$ & $99.88 \%$ & $99.77 \%$ \\
\hline Ratio & Rural & $99.57 \%$ & $97.80 \%$ & $100.84 \%$ & $100.16 \%$ & $99.39 \%$ & $101.58 \%$ & & & $100.20 \%$ & $101.53 \%$ \\
\hline
\end{tabular}

Table 16 Urban Mean and Median Weekly Hours of Household Production, 2009 ENUT and Matched File

\begin{tabular}{|c|c|c|c|c|c|c|}
\hline \multicolumn{4}{|c|}{ Mean values of HH Production } & & & \\
\hline Urban & ENUT09 & Match & Ratio & & & \\
\hline HH Production & 27.0 & 27.0 & $100.0 \%$ & & & \\
\hline Core & 17.9 & 17.9 & $99.7 \%$ & & & \\
\hline Care & 7.6 & 7.7 & $100.8 \%$ & & & \\
\hline Procurement & 1.5 & 1.5 & $99.3 \%$ & & & \\
\hline Personal & 75.3 & 75.2 & $99.8 \%$ & & & \\
\hline \multicolumn{4}{|c|}{ Distribution among population subgroups } & \multicolumn{3}{|c|}{ Ratio of Mean Values } \\
\hline & & & & & ENUT09 & Match \\
\hline \multicolumn{7}{|l|}{ Number of Children } \\
\hline 0 & 24.33 & 24.34 & $100.0 \%$ & $0 / 3+$ & 0.77 & 0.79 \\
\hline 1 & 27.30 & 27.21 & $99.7 \%$ & $1 / 3+$ & 0.87 & 0.88 \\
\hline 2 & 30.13 & 29.92 & $99.3 \%$ & $2 / 3+$ & 0.96 & 0.97 \\
\hline $3+$ & 31.48 & 30.90 & $98.2 \%$ & & & \\
\hline \multicolumn{7}{|l|}{ Number of Adults } \\
\hline 1 & 26.76 & 27.34 & $102.2 \%$ & $2 / 1$ & 1.15 & 1.12 \\
\hline 2 & 30.72 & 30.68 & $99.9 \%$ & $3+/ 1$ & 0.93 & 0.91 \\
\hline $3+$ & 24.95 & 24.75 & $99.2 \%$ & & & \\
\hline \multicolumn{7}{|c|}{ Presence of Non-Employed Adult? } \\
\hline No & 25.00 & 25.43 & $101.7 \%$ & Yes/No & 1.11 & 1.08 \\
\hline Yes & 27.67 & 27.59 & $99.7 \%$ & & & \\
\hline \multicolumn{7}{|c|}{ Within Poverty Band? } \\
\hline No & 26.39 & 26.47 & $100.3 \%$ & Yes/No & 1.08 & 1.06 \\
\hline Yes & 28.40 & 28.08 & $98.9 \%$ & & & \\
\hline Household Income & & & & & \multicolumn{2}{|c|}{ Over All } \\
\hline$L T 1,000$ & 29.98 & 28.54 & $95.2 \%$ & LT 1,000 & 1.11 & 1.06 \\
\hline $1,000-1,599$ & 30.04 & 29.84 & $99.3 \%$ & $1,000-1,599$ & 1.11 & 1.10 \\
\hline $1,600-2,299$ & 29.90 & 29.62 & $99.1 \%$ & $1,600-2,299$ & 1.11 & 1.10 \\
\hline $2,300-3,499$ & 26.61 & 26.39 & $99.2 \%$ & $2,300-3,499$ & 0.98 & 0.98 \\
\hline GE 3,500 & 23.26 & 23.83 & $102.5 \%$ & GE 3,500 & 0.86 & 0.88 \\
\hline \multicolumn{7}{|l|}{ Employed? } \\
\hline No & 33.35 & 33.78 & $101.3 \%$ & Yes/No & 0.63 & 0.63 \\
\hline Yes & 21.08 & 21.33 & $101.2 \%$ & & & \\
\hline \multicolumn{7}{|l|}{ Sex } \\
\hline Female & 39.81 & 39.67 & $99.6 \%$ & Female/Male & 3.13 & 3.03 \\
\hline Male & 12.72 & 13.10 & $103.0 \%$ & & & \\
\hline
\end{tabular}




\begin{tabular}{|c|c|c|c|c|c|c|}
\hline \multicolumn{4}{|c|}{ Median values of HH Production } & & & \\
\hline Urban & ENUT09 & Match & Ratio & & & \\
\hline HH Production & 17.3 & 17.2 & $99.8 \%$ & & & \\
\hline Core & 11.2 & 11.1 & $99.3 \%$ & & & \\
\hline Care & 0.0 & 0.0 & \#DIV/O! & & & \\
\hline Procurement & 0.9 & 0.9 & $100.0 \%$ & & & \\
\hline Personal & 73.1 & 73.0 & $99.9 \%$ & & & \\
\hline \multicolumn{4}{|c|}{ Distribution among population subgroups } & \multicolumn{3}{|c|}{ Ratio of Mean Values } \\
\hline & & & & & ENUT09 & Match \\
\hline \multicolumn{7}{|l|}{ Number of Children } \\
\hline 0 & 16.47 & 16.38 & $99.5 \%$ & $0 / 3+$ & 0.91 & 0.90 \\
\hline 1 & 17.33 & 17.31 & $99.9 \%$ & $1 / 3+$ & 0.96 & 0.95 \\
\hline 2 & 18.77 & 18.55 & $98.8 \%$ & $2 / 3+$ & 1.04 & 1.02 \\
\hline $3+$ & 18.13 & 18.14 & $100.1 \%$ & & & \\
\hline \multicolumn{7}{|l|}{ Number of Adults } \\
\hline 1 & 21.68 & 21.86 & $100.8 \%$ & $2 / 1$ & 0.97 & 0.96 \\
\hline 2 & 21.09 & 21.06 & $99.9 \%$ & $3+/ 1$ & 0.68 & 0.66 \\
\hline $3+$ & 14.70 & 14.47 & $98.4 \%$ & & & \\
\hline \multicolumn{7}{|c|}{$\begin{array}{l}\text { Presence of Non-Employed Adult? } \\
\end{array}$} \\
\hline No & 18.73 & 18.83 & $100.5 \%$ & Yes/No & 0.89 & 0.88 \\
\hline Yes & 16.70 & 16.54 & $99.0 \%$ & & & \\
\hline \multicolumn{7}{|c|}{ Within Poverty Band? } \\
\hline No & 16.91 & 16.88 & $99.8 \%$ & Yes/No & 1.07 & 1.07 \\
\hline Yes & 18.16 & 17.98 & $99.0 \%$ & & & \\
\hline Household Income & & & & & \multicolumn{2}{|c|}{ Over All } \\
\hline$L T 1,000$ & 21.95 & 20.96 & $95.5 \%$ & $L T 1,000$ & 1.27 & 1.22 \\
\hline $1,000-1,599$ & 20.83 & 20.30 & $97.5 \%$ & $1,000-1,599$ & 1.21 & 1.18 \\
\hline $1,600-2,299$ & 19.81 & 19.20 & $96.9 \%$ & $1,600-2,299$ & 1.15 & 1.11 \\
\hline $2,300-3,499$ & 16.98 & 16.89 & $99.5 \%$ & $2,300-3,499$ & 0.98 & 0.98 \\
\hline GE 3,500 & 14.15 & 14.39 & $101.7 \%$ & GE 3,500 & 0.82 & 0.84 \\
\hline \multicolumn{7}{|l|}{ Employed? } \\
\hline No & 23.54 & 24.13 & $102.5 \%$ & Yes/No & 0.60 & 0.59 \\
\hline Yes & 14.23 & 14.21 & $99.9 \%$ & & & \\
\hline \multicolumn{7}{|l|}{ Sex } \\
\hline Female & 36.44 & 36.18 & $99.3 \%$ & Female/Male & 4.52 & 4.44 \\
\hline Male & 8.06 & 8.15 & $101.1 \%$ & & & \\
\hline
\end{tabular}


Table 17 Rural Mean and Median Weekly Hours of Household Production, 2009 ENUT and Matched File

\begin{tabular}{|c|c|c|c|c|c|c|}
\hline \multicolumn{4}{|c|}{ Mean values of HH Production } & & & \\
\hline Rural & ENUT09 & Match & Ratio & & & \\
\hline HH Production & 32.5 & 32.3 & $99.4 \%$ & & & \\
\hline Core & 23.2 & 23.1 & $99.6 \%$ & & & \\
\hline Care & 8.2 & 8.0 & $97.8 \%$ & & & \\
\hline Procurement & 1.2 & 1.2 & $100.8 \%$ & & & \\
\hline Personal & 81.7 & 81.8 & $100.2 \%$ & & & \\
\hline \multicolumn{4}{|c|}{ Distribution among population subgroups } & \multicolumn{3}{|c|}{ Ratio of Mean Values } \\
\hline & & & & & ENUT09 & Match \\
\hline \multicolumn{7}{|l|}{ Number of Children } \\
\hline 0 & 30.53 & 30.59 & $100.2 \%$ & $0 / 3+$ & 0.88 & 0.90 \\
\hline 1 & 32.39 & 32.13 & $99.2 \%$ & $1 / 3+$ & 0.94 & 0.95 \\
\hline 2 & 33.88 & 33.35 & $98.4 \%$ & $2 / 3+$ & 0.98 & 0.98 \\
\hline $3+$ & 34.63 & 33.90 & $97.9 \%$ & & & \\
\hline \multicolumn{7}{|l|}{ Number of Adults } \\
\hline 1 & 34.50 & 35.03 & $101.5 \%$ & $2 / 1$ & 1.05 & 1.03 \\
\hline 2 & 36.09 & 36.00 & $99.8 \%$ & $3+/ 1$ & 0.86 & 0.84 \\
\hline $3+$ & 29.59 & 29.51 & $99.7 \%$ & & & \\
\hline \multicolumn{7}{|c|}{ Presence of Non-Employed Adult? } \\
\hline No & 28.93 & 31.09 & $107.5 \%$ & Yes/No & 1.14 & 1.05 \\
\hline Yes & 33.09 & 32.63 & $98.6 \%$ & & & \\
\hline \multicolumn{7}{|c|}{ Within Poverty Band? } \\
\hline No & 32.61 & 32.34 & $99.2 \%$ & Yes/No & 0.99 & 1.00 \\
\hline Yes & 32.40 & 32.34 & $99.8 \%$ & & & \\
\hline Household Income & & & & & \multicolumn{2}{|c|}{ Over All } \\
\hline$L T 1,000$ & 35.48 & 34.31 & $96.7 \%$ & $L T 1,000$ & 1.09 & 1.06 \\
\hline $1,000-1,599$ & 33.86 & 33.60 & $99.2 \%$ & $1,000-1,599$ & 1.04 & 1.04 \\
\hline $1,600-2,299$ & 31.82 & 31.37 & $98.6 \%$ & $1,600-2,299$ & 0.98 & 0.97 \\
\hline $2,300-3,499$ & 29.14 & 28.48 & $97.7 \%$ & $2,300-3,499$ & 0.90 & 0.88 \\
\hline GE 3,500 & 27.48 & 28.81 & $104.8 \%$ & GE 3,500 & 0.84 & 0.89 \\
\hline \multicolumn{7}{|l|}{ Employed? } \\
\hline No & 41.93 & 41.99 & $100.1 \%$ & Yes/No & 0.46 & 0.53 \\
\hline Yes & 19.37 & 22.30 & $115.1 \%$ & & & \\
\hline \multicolumn{7}{|l|}{ Sex } \\
\hline Female & 50.87 & 49.44 & $97.2 \%$ & Female/Male & 3.94 & 3.54 \\
\hline Male & 12.90 & 13.95 & $108.1 \%$ & & & \\
\hline
\end{tabular}




\begin{tabular}{|c|c|c|c|c|c|c|}
\hline \multicolumn{4}{|c|}{ Median values of HH Production } & & & \\
\hline Rural & ENUT09 & Match & Ratio & & & \\
\hline HH Production & 21.6 & 21.9 & $101.5 \%$ & & & \\
\hline Core & 15.2 & 15.4 & $101.6 \%$ & & & \\
\hline Care & 0.0 & 0.0 & \#DIV/O! & & & \\
\hline Procurement & 0.0 & 0.0 & \#DIV/O! & & & \\
\hline Personal & 78.8 & 79.0 & $100.2 \%$ & & & \\
\hline \multicolumn{4}{|c|}{ Distribution among population subgroups } & \multicolumn{3}{|c|}{ Ratio of Mean Values } \\
\hline & & & & & ENUT09 & Match \\
\hline \multicolumn{7}{|l|}{ Number of Children } \\
\hline 0 & 23.19 & 23.48 & $101.3 \%$ & $0 / 3+$ & 1.13 & 1.10 \\
\hline 1 & 20.98 & 21.04 & $100.3 \%$ & $1 / 3+$ & 1.02 & 0.98 \\
\hline 2 & 20.70 & 20.31 & $98.1 \%$ & $2 / 3+$ & 1.01 & 0.95 \\
\hline $3+$ & 20.54 & 21.44 & $104.4 \%$ & & & \\
\hline \multicolumn{7}{|l|}{ Number of Adults } \\
\hline 1 & 28.12 & 28.77 & $102.3 \%$ & $2 / 1$ & 0.91 & 0.88 \\
\hline 2 & 25.46 & 25.46 & $100.0 \%$ & $3+/ 1$ & 0.65 & 0.66 \\
\hline $3+$ & 18.40 & 19.10 & $103.8 \%$ & & & \\
\hline \multicolumn{7}{|c|}{$\begin{array}{l}1 \\
\text { Presence of Non-Employed Adult? }\end{array}$} \\
\hline No & 22.03 & 23.98 & $108.9 \%$ & Yes/No & 0.98 & 0.88 \\
\hline Yes & 21.48 & 21.21 & $98.7 \%$ & & & \\
\hline \multicolumn{7}{|c|}{ Within Poverty Band? } \\
\hline No & 22.30 & 22.25 & $99.8 \%$ & Yes/No & 0.91 & 0.95 \\
\hline Yes & 20.27 & 21.21 & $104.6 \%$ & & & \\
\hline Household Income & & & & & \multicolumn{2}{|c|}{ Over All } \\
\hline$L T 1,000$ & 27.83 & 26.30 & $94.5 \%$ & $L T 1,000$ & 1.29 & 1.20 \\
\hline $1,000-1,599$ & 22.54 & 22.72 & $100.8 \%$ & $1,000-1,599$ & 1.04 & 1.04 \\
\hline $1,600-2,299$ & 19.14 & 19.67 & $102.8 \%$ & $1,600-2,299$ & 0.89 & 0.90 \\
\hline $2,300-3,499$ & 17.37 & 16.65 & $95.9 \%$ & $2,300-3,499$ & 0.80 & 0.76 \\
\hline$G E 3,500$ & 16.27 & 17.47 & $107.4 \%$ & GE 3,500 & 0.75 & 0.80 \\
\hline \multicolumn{7}{|l|}{ Employed? } \\
\hline No & 39.72 & 39.86 & $100.4 \%$ & Yes/No & 0.29 & 0.33 \\
\hline Yes & 11.64 & 13.26 & $113.9 \%$ & & & \\
\hline \multicolumn{7}{|l|}{ Sex } \\
\hline Female & 51.39 & 49.34 & $96.0 \%$ & Female/Male & 6.09 & 5.45 \\
\hline Male & 8.44 & 9.05 & $107.2 \%$ & & & \\
\hline
\end{tabular}


Table 18 Household Production Weekly Hours for Households in Reference Group, Ratio of Matched File to 2009 ENUT

\begin{tabular}{|c|c|c|c|c|c|c|c|}
\hline & & & & Num & $\mathrm{r}$ of $\mathrm{Ch}$ & Iren & \\
\hline & $\begin{array}{c}\text { Number of } \\
\text { Adults }\end{array}$ & & 0 & 1 & 2 & $3+$ & All \\
\hline & 1 & Mean & $100.4 \%$ & $69.7 \%$ & $74.0 \%$ & $84.9 \%$ & $100.9 \%$ \\
\hline & 1 & Median & $100.0 \%$ & $25.7 \%$ & $59.2 \%$ & $70.2 \%$ & $94.6 \%$ \\
\hline & $?$ & Mean & $102.5 \%$ & $100.8 \%$ & $102.0 \%$ & $97.6 \%$ & $98.9 \%$ \\
\hline & 2 & Median & $101.2 \%$ & $98.6 \%$ & $100.2 \%$ & $93.0 \%$ & $93.9 \%$ \\
\hline Urban & $2+$ & Mean & $104.1 \%$ & $109.1 \%$ & $105.0 \%$ & $107.0 \%$ & $104.7 \%$ \\
\hline & $3+$ & Median & $107.5 \%$ & $116.0 \%$ & $99.1 \%$ & $106.2 \%$ & $106.7 \%$ \\
\hline & & Mean & $103.9 \%$ & $104.3 \%$ & $100.6 \%$ & $100.0 \%$ & $101.9 \%$ \\
\hline & RII & Median & $103.4 \%$ & $103.8 \%$ & $98.1 \%$ & $95.8 \%$ & $98.7 \%$ \\
\hline & 1 & Mean & $90.8 \%$ & $92.8 \%$ & $66.2 \%$ & $91.0 \%$ & $85.8 \%$ \\
\hline & 1 & \begin{tabular}{|l|} 
Median \\
\end{tabular} & $94.8 \%$ & $106.1 \%$ & $73.9 \%$ & $83.7 \%$ & $92.2 \%$ \\
\hline & 2 & Mean & $95.7 \%$ & $99.3 \%$ & $112.1 \%$ & $110.2 \%$ & $102.3 \%$ \\
\hline Rural & 2 & Median & $99.9 \%$ & $98.8 \%$ & $101.8 \%$ & $96.2 \%$ & $92.1 \%$ \\
\hline Rural & $3+$ & Mean & $105.4 \%$ & $110.3 \%$ & $109.4 \%$ & $103.3 \%$ & $107.0 \%$ \\
\hline & 2ד & Median & $105.2 \%$ & $118.8 \%$ & $105.7 \%$ & $104.4 \%$ & $106.4 \%$ \\
\hline & & Mean & $99.4 \%$ & $103.3 \%$ & $107.7 \%$ & $108.4 \%$ & $103.3 \%$ \\
\hline & All & \begin{tabular}{|l|l} 
Median \\
\end{tabular} & $99.1 \%$ & $100.3 \%$ & $99.8 \%$ & $101.9 \%$ & $96.9 \%$ \\
\hline
\end{tabular}




\section{FIGURES}

Figure 1 Ratio of Mean HH Production by Category (Match/UT 2005)

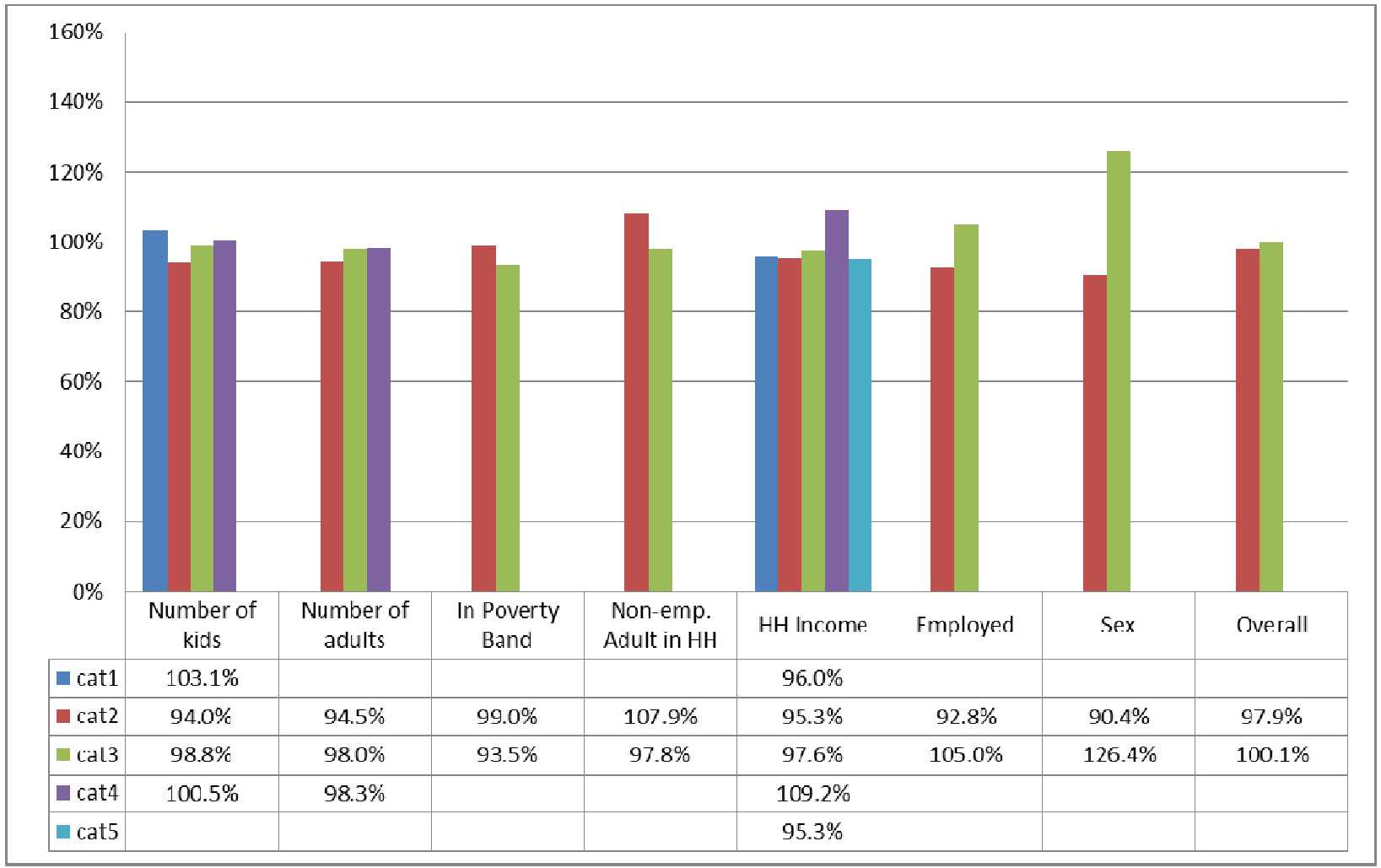


Figure 2 Household Production by Matching Cells, UT 2005 and Matched File

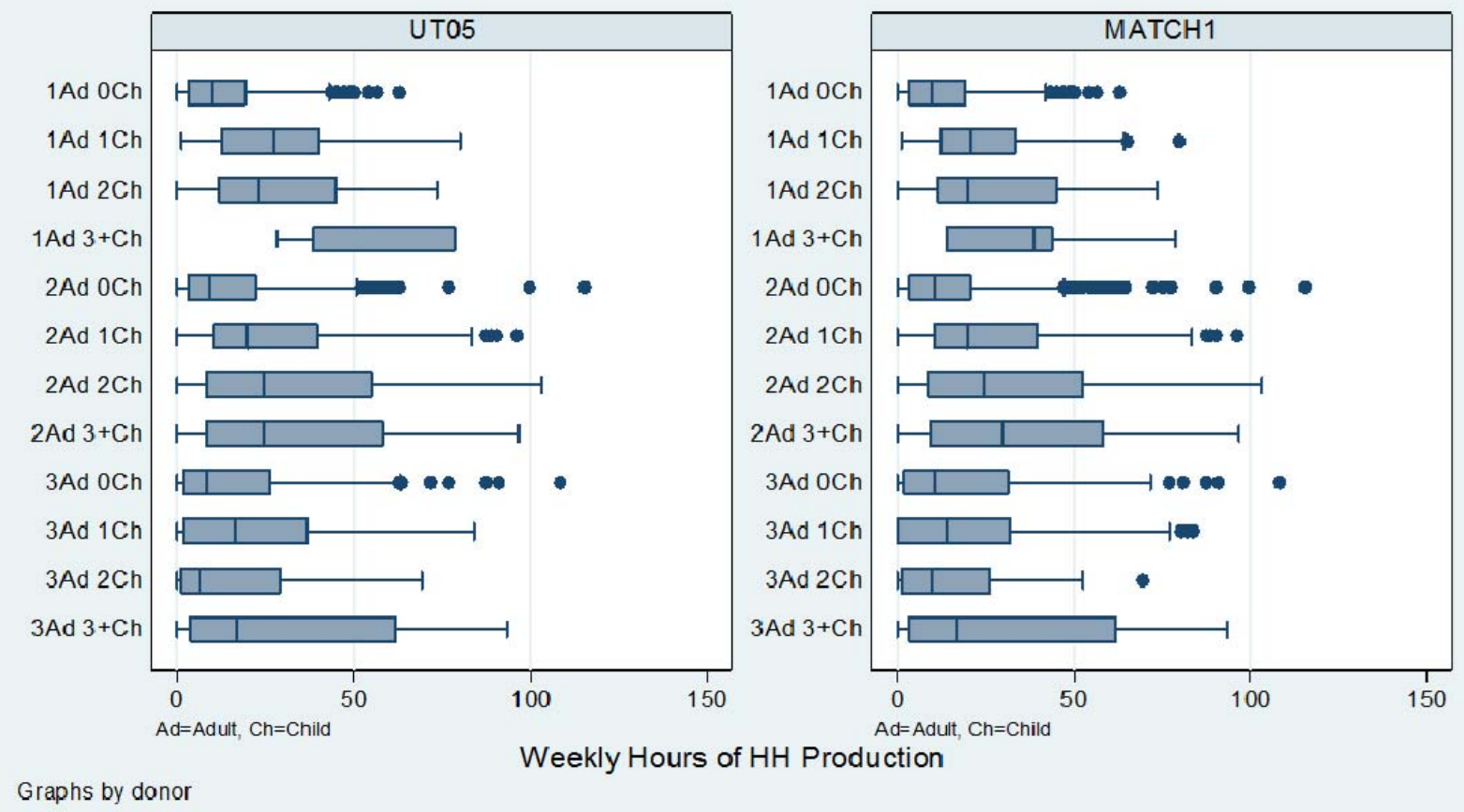

Figure 3 Ratio of Mean HH Production by Category (Match/EUT 2007)

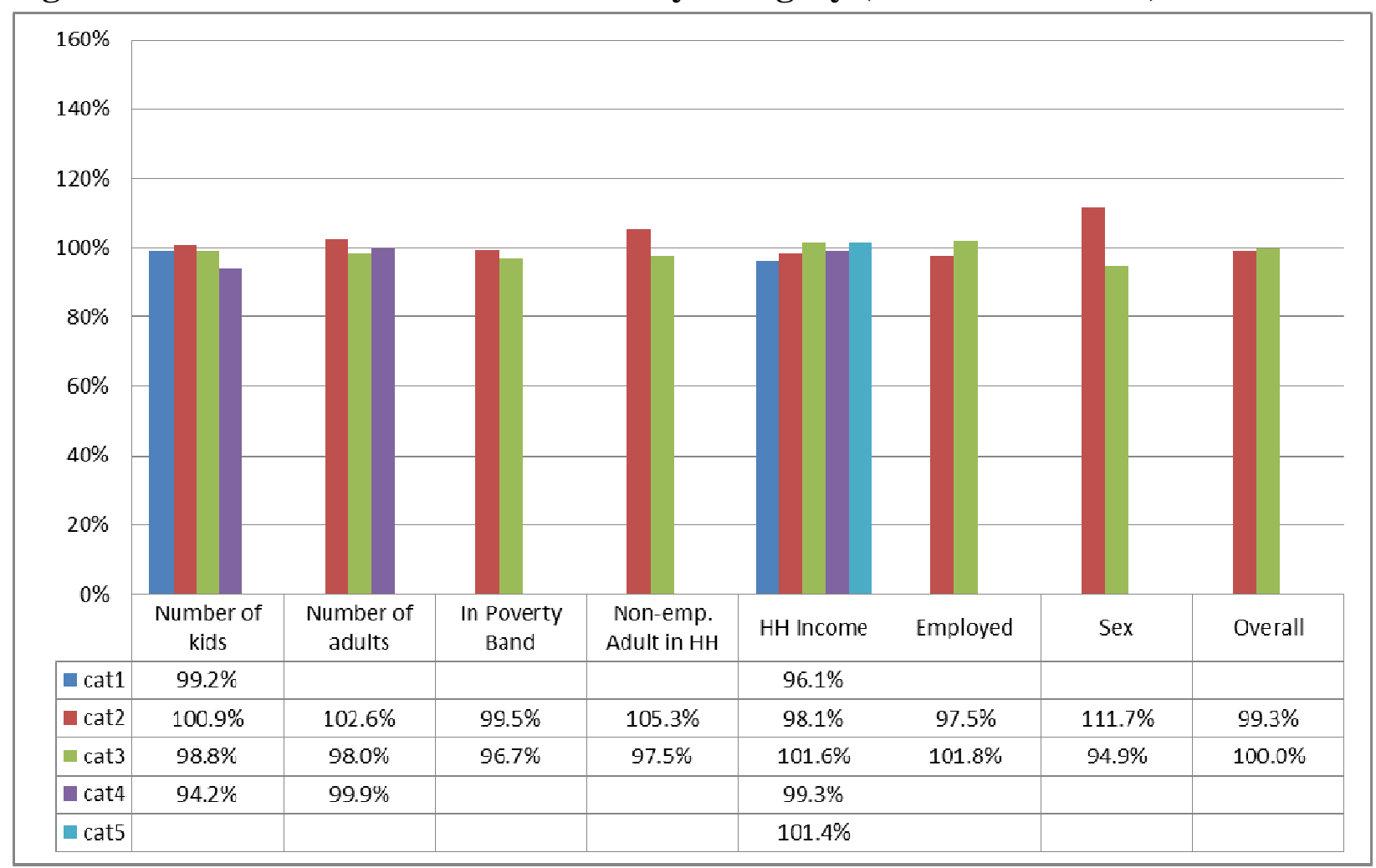


Figure 4 Household Production by Matching Cells, EUT 2007 and Matched File

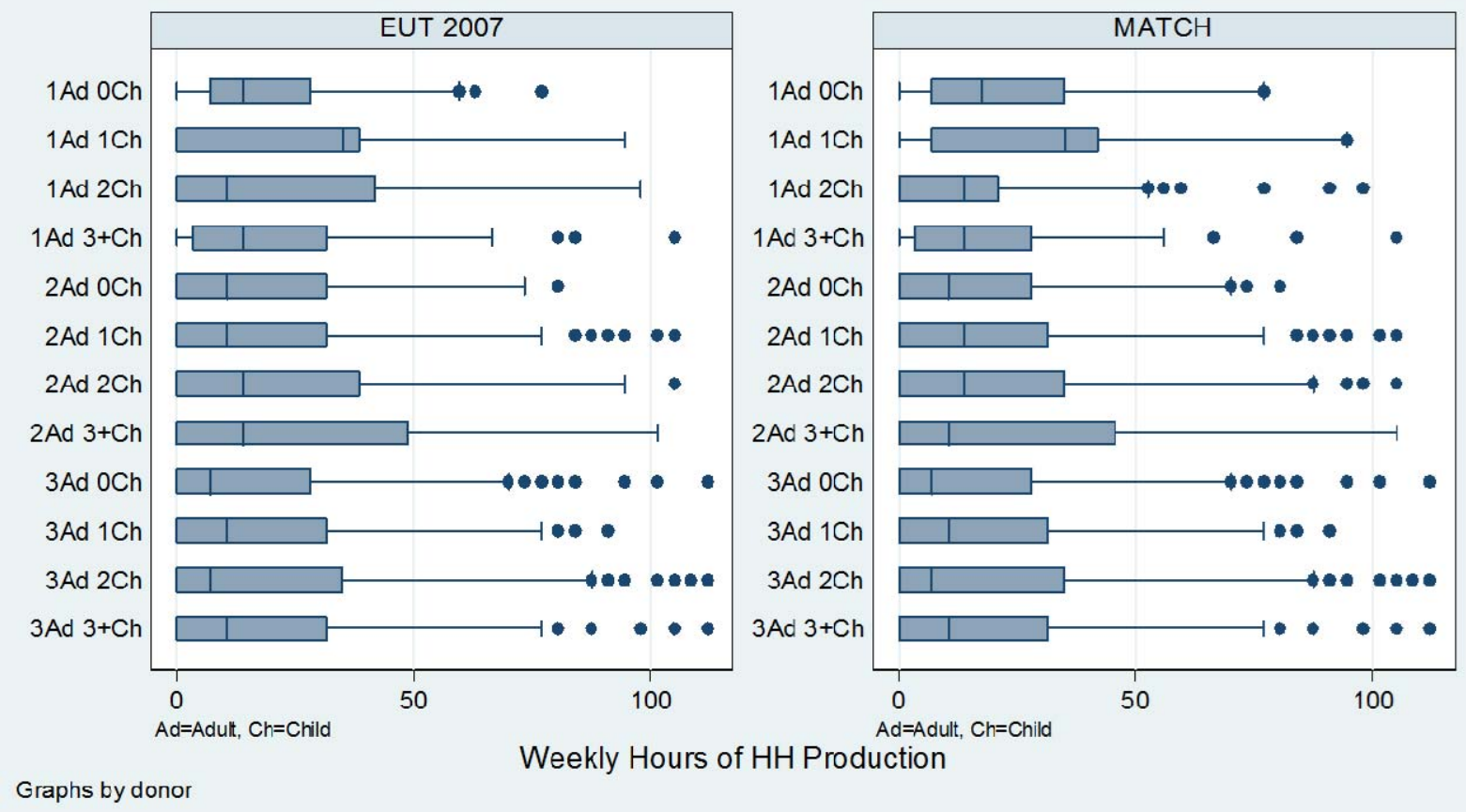

Figure 5 Ratio of Mean HH Production by Category (Match/ENUT 2009)

\section{a. Urban}

\begin{tabular}{|c|c|c|c|c|c|c|c|c|}
\hline \multicolumn{9}{|l|}{$160 \%$} \\
\hline \multicolumn{9}{|l|}{$140 \%$} \\
\hline \multicolumn{9}{|l|}{$120 \%$} \\
\hline \multicolumn{9}{|l|}{$100 \%$} \\
\hline & & & & & 10 & 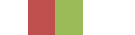 & 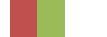 & \\
\hline $80 \%$ & & & & & 10 & t & & \\
\hline $60 \%$ & & & & & 10 & 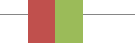 & 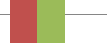 & 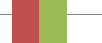 \\
\hline $40 \%$ & & & & & 1 & 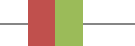 & 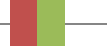 & 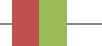 \\
\hline $20 \%$ & & & & & & & & \\
\hline $0 \%$ & $\begin{array}{l}\text { Number of } \\
\text { kids }\end{array}$ & $\begin{array}{l}\text { Number of } \\
\text { adults }\end{array}$ & $\begin{array}{l}\text { In Poverty } \\
\text { Band }\end{array}$ & $\begin{array}{l}\text { Non-emp. } \\
\text { Adult in HH }\end{array}$ & $\mathrm{HH}$ Income & Employed & Sex & Overall \\
\hline cat 1 & $100.0 \%$ & & & & $95.2 \%$ & & & \\
\hline cat2 & $99.7 \%$ & $102.2 \%$ & $100.3 \%$ & $101.7 \%$ & $99.3 \%$ & $101.3 \%$ & $99.6 \%$ & $100.0 \%$ \\
\hline cat3 & $99.3 \%$ & $99.9 \%$ & $98.9 \%$ & $99.7 \%$ & $99.1 \%$ & $101.2 \%$ & $103.0 \%$ & $99.8 \%$ \\
\hline a cat 4 & $98.2 \%$ & $99.2 \%$ & & & $99.2 \%$ & & & \\
\hline cat5 & & & & & $102.5 \%$ & & & \\
\hline
\end{tabular}




\section{b. Rural}

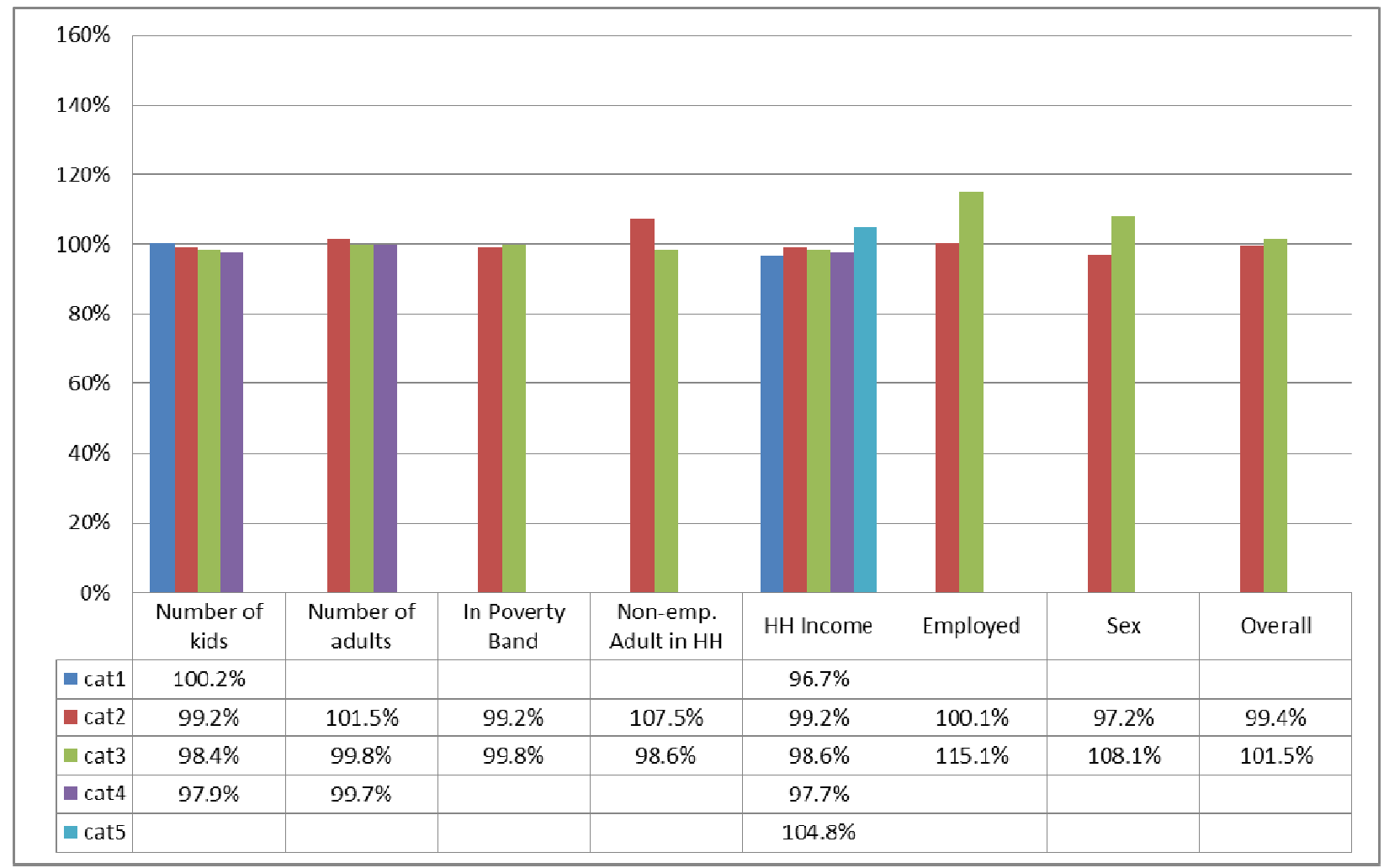

Figure 6 Household Production by Matching Cells, ENUT 2009 and Matched File
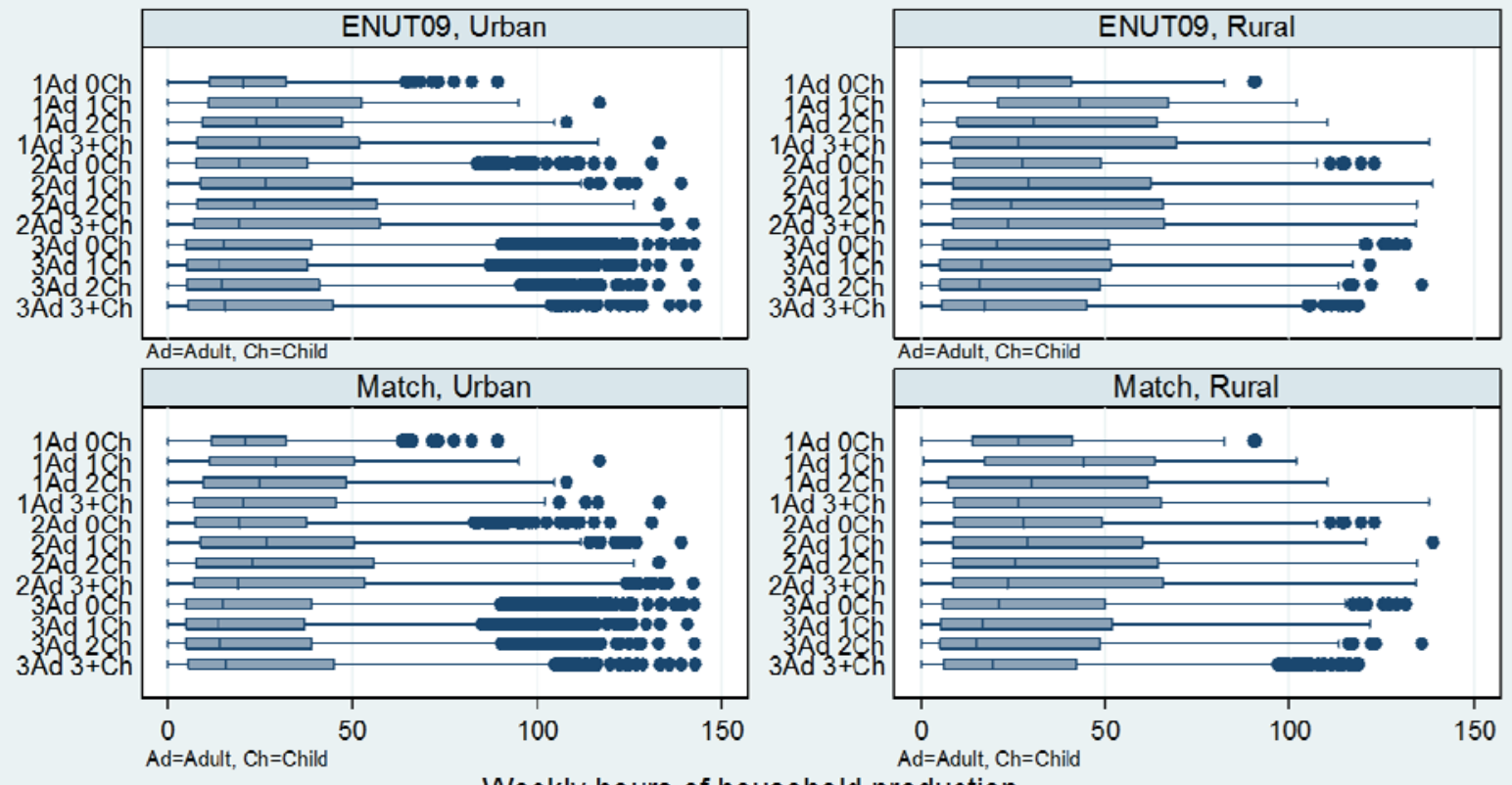

Graphs by Donor and Rural household? 